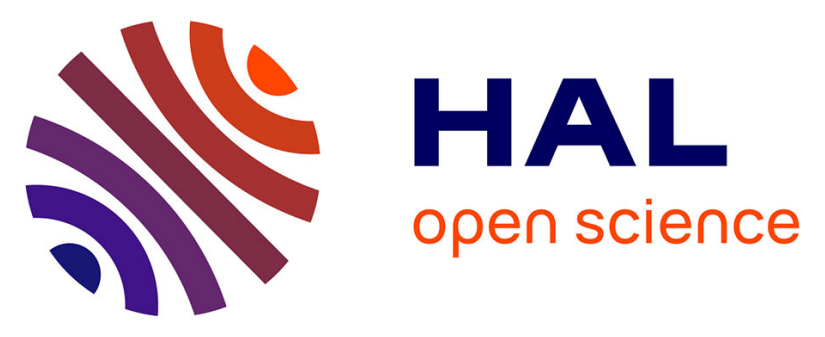

\title{
Semi-batch Terpolymerization of Ethylene, Propylene, and 5-Ethylidene-2-norbornene: Heterogeneous High-Ethylene EPDM Thermoplastic Elastomers
}

Giuseppe Leone, Giorgia Zanchin, Rocco Di Girolamo, Fabio de Stefano, Christian Lorber, Claudio de Rosa, Giovanni Ricci, Fabio Bertini

\section{To cite this version:}

Giuseppe Leone, Giorgia Zanchin, Rocco Di Girolamo, Fabio de Stefano, Christian Lorber, et al.. Semi-batch Terpolymerization of Ethylene, Propylene, and 5-Ethylidene-2-norbornene: Heterogeneous High-Ethylene EPDM Thermoplastic Elastomers. Macromolecules, 2020, 53 (14), pp.5881-5894. 10.1021/acs.macromol.0c01123 . hal-02909436

\section{HAL Id: hal-02909436 \\ https://hal.science/hal-02909436}

Submitted on 27 Oct 2020

HAL is a multi-disciplinary open access archive for the deposit and dissemination of scientific research documents, whether they are published or not. The documents may come from teaching and research institutions in France or abroad, or from public or private research centers.
L'archive ouverte pluridisciplinaire HAL, est destinée au dépôt et à la diffusion de documents scientifiques de niveau recherche, publiés ou non, émanant des établissements d'enseignement et de recherche français ou étrangers, des laboratoires publics ou privés. 


\title{
Semi-Batch Terpolymerization of Ethylene, Propylene and 5-Ethylidene-2-Norbornene: Heterogeneous High-Ethylene EPDM Thermoplastic Elastomers
}

\author{
Giuseppe Leone, ${ }^{a,}$ Giorgia Zanchin, ${ }^{a}$ Rocco Di Girolamo, ${ }^{b}$ Fabio De Stefano, ${ }^{b}$ \\ Christian Lorber, ${ }^{c, d}$ Claudio De Rosa,${ }^{b}$ Giovanni Ricci, ${ }^{a}$ Fabio Bertini ${ }^{a}{ }^{*}$
}

${ }^{a}$ CNR, Istituto di Scienze e Tecnologie Chimiche "Giulio Natta” (SCITEC), via A. Corti 12, I-20133 Milano, Italy.

${ }^{b}$ Dipartimento di Scienze Chimiche, Università di Napoli “Federico II”, Complesso Monte S. Angelo, via Cintia, I80126 Napoli, Italy.

${ }^{c}$ CNRS, LCC (Laboratoire de Chimie de Coordination), 205 route de Narbonne, BP44099, 31077 Toulouse, France

${ }^{d}$ Université de Toulouse, UPS, INPT, LCC, 31077 Toulouse, France.

* Corresponding authors

E-mail address: giuseppe.leone@ scitec.cnr.it (G. Leone)

E-mail address: fabio.bertini@scitec.cnr.it (F. Bertini)

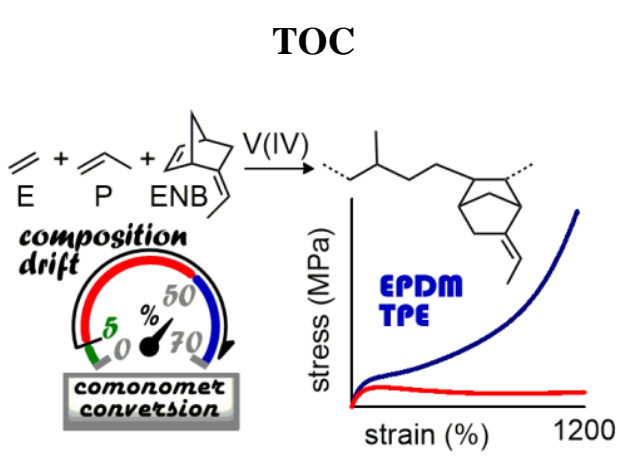

\begin{abstract}
Thermoplastic elastomers (TPEs) are materials combining the processability of thermoplastics and the elasticity of rubbers. The global value and demand of TPEs is expected to grow in coming years, and advancement in synthetic chemistry is the key driving force. This contribution provides a simple synthesis of high-ethylene EPDMs with high molecular weight, narrow molecular weight distribution $\left(1.9<M_{\mathrm{w}} / M_{\mathrm{n}}<2.3\right)$, and properties which can be adjusted from soft thermoplastic to elastomer. EPDMs are prepared through the terpolymerization of ethylene with propylene and 5ethylidene-2-norbornene (ENB), where ethylene is continuously supplied to the reaction bath, while
\end{abstract}


propylene and ENB are added only at the beginning. Polymerizations are catalyzed by three known imido vanadium(IV), differing in the imido substituents and coligand, in combination with $\mathrm{Et}_{2} \mathrm{AlCl}$ and $\mathrm{Cl}_{3} \mathrm{CCO}_{2}$ Et. The obtained EPDMs are a mixture of macromolecules each of them featuring a non random comonomer distribution, and non uniform composition. Each chain likely contains multiblocks where the comonomers are segmented, i.e., blocks with high ethylene content that may crystallize, and blocks with high propylene and ENB content that may not crystallize. This broad chemical composition distribution is due to time drift that occurs during the polymerization, which in turn depends on the experimental conditions and ligand set. Composition drift causes variation in the instantaneous feed comonomer ratio, and hence in the chemical composition of the terpolymer over the period of conversion. In proper experimental conditions, EPDMs behave as TPEs without the need of vulcanization, polymer blending, and reinforcement through the addition of fillers. They exhibit high elongation at break, strain hardening at large deformation, remarkable shape retention properties (up to $76 \%$ recovery after 10 cycles at $300 \%$, and about $90 \%$ at $410 \%$ strain), and remelting processability with no fall in properties for recycle and reuse. 


\section{INTRODUCTION}

The emergence of TPEs in the late 1950s provided a new horizon to the field of polymer chemistry and technology. TPEs are an important class of rubbery materials that combine the processing advantages and recycling potential of thermoplastics with the flexibility, low modulus, and soft touch of elastomers. TPEs can be repeatedly stretched without permanent deformation and do not require curing or vulcanization. Over the past two decades, many companies have focused their research on TPEs for specific market applications, and the toolbox of polymer chemistry has been boosted by developments in polymerization techniques and catalysts. ${ }^{1-8}$

Based on chemical building blocks there are several commercially available TPEs; two generic classes are block copolymers (styrenics, polyesters, polyurethanes, and polyamides) and thermoplastic/elastomer blends. Among these, polyolefin TPEs have received considerable attention because of wide availability of commodity olefins, high chemical resistance, low density and reversible shape memory that make polyolefin TPEs desirable in several applications ranging from biomedical devices to packaging, adhesives, lightweight engineering plastics for automotive, textiles, and in additive manufacturing techniques such as 3D printing. ${ }^{9-18}$

Blend of EPDM with poly(ethylene) (PE) or poly(propylene (PP) are a family of engineering polyolefinic materials, and one of the most important in today's market. ${ }^{19-22}$ EPDM is a synthetic terpolymer rubber of ethylene, propylene and a non-conjugated diene, usually 5ethylidene-2-norbornene (ENB). ${ }^{23,24}$ EPDM market has grown tremendously, and today EPDM is the largest synthetic non-tire rubber with a volume of about $1200 \mathrm{kton} / \mathrm{yr}$ for application in the automotive components, building packing, and electrical cable. EPDM combine a saturated polymer backbone with residual unsaturations as side groups. As a consequence, EPDM is more resistant to oxygen, ozone, UV, and heat than commodity rubbers. ${ }^{25,26}$ However, EPDMs have quite poor mechanical properties, and, therefore, most of EPDM applications requires reinforcement in blend with PE or PP thermoplastics to improve, as an example, the tensile strength, and cross-linking by using sulfur or peroxides. Sulphur vulcanization leads to a dramatic improvement in the thermal 
stability, and mechanical properties, but irreversible permanent cross-link is a disadvantage to the recyclability nature of the rubber. ${ }^{27}$

Generally, EPDMs are designed according to the following criteria: $(i)$ ethylene/propylene ratio, (ii) diene content, and (iii) viscosity, which in turn strongly affects the properties of raw EPDM rubbers as well as those of the corresponding vulcanizates. The ethylene/propylene ratio is thought to have the greatest effect on EPDM properties and applications. At high propylene level (above $50 \mathrm{wt} \%$ ), short ethylene sequences exist in the main backbone chain so crystallinity is absent, while a small amount of crystallinity is present at low propylene level (usually below 35 wt\%). If ethylene and propylene contents are approximately equal, the (co)monomers are evenly distributed, and the polymer is amorphous with a low glass transition temperature (even lower than $-60{ }^{\circ} \mathrm{C}$ ) and remarkably superior cold resistance for outdoor applications (e.g., automotive and construction). ${ }^{28}$

EPDMs are manufactured commercially in solution, slurry and gas-phase processes. Conventional Ziegler-Natta catalysts based on Group 4 metals and Vanadium are commercially used for most of these processes. Among them, homogeneous vanadium catalysts are of great importance. These catalytic systems are derived from a combination of vanadium compounds (e.g., $\mathrm{VCl}_{4}, \mathrm{VOCl}_{3}, \mathrm{VO}(\mathrm{OR})_{3}, \mathrm{~V}(\mathrm{acac})_{3}, \mathrm{R}=$ alkyl group, acac $=$ acetylacetonate $)$ and alkyl aluminum halide (typically $\mathrm{Et}_{2} \mathrm{AlCl}$ ) or aluminum hydride derivatives, and a Lewis base (e.g., anisole). ${ }^{29-34}$

Herein, we report the terpolymerization of ethylene with propylene and ENB catalyzed by known imido vanadium(IV) complexes, ${ }^{35,36}$ differing in the ligand substitution, in combination with $\mathrm{Et}_{2} \mathrm{AlCl}$ and $\mathrm{Cl}_{3} \mathrm{CCO}_{2} \mathrm{Et}$ (ETA). The polymerizations have been carried out in a semi-batch mode where ethylene is continuously supplied to the polymerization mixture and its pressure is kept constant, while liquid propylene and ENB are added only at the beginning. Because of the feed policy, the high initiation rate and fast comonomer consumption, the resultant EPDMs are heterogeneous in composition: the terpolymers are composed of chains rich in propylene and ENB initially formed when their concentration is at maximum, and ethylene-rich chains formed at the 
end, when very low amount of comonomers left in the reaction mixture. This is due to the composition drift that occurs during the reaction, which strongly depends on polymerization conditions and ligand set. In proper experimental conditions, the time drift in composition allows the formation of ethylene sequences, sufficiently long to offer reinforcement to the soft amorphous phase, but not long enough to become detrimental to the terpolymer properties as it occurs when the comonomer conversion was higher than $60 \%$. The obtained EPDMs behave as TPEs with properties close to those of EPDM/PE blend $(80 / 20 \mathrm{wt} \%),{ }^{20}$ but without the need of polymers blending and reinforcement through the addition of active fillers. In particular, they exhibit high elongation at break, strain hardening at large deformation, excellent shape retention properties (up to $76 \%$ recovery after 10 cycles at $300 \%$, and about $90 \%$ at $410 \%$ strain), and remelting processability with no fall in properties for recycle use.

Conclusive considerations should take into account that, beyond the uncertainty of comonomer positioning due to the time drift in composition, keeping the comonomer conversion at high level (up to $80 \%$ ) reduces costs and minimizes waste, and offers an easy way to tune the properties of EPDM from soft thermoplastic to elastomer, which are of great importance for various applications.

\section{EXPERIMENTAL}

General Procedures and Materials. Manipulations of air- and/or moisture-sensitive materials were carried out under an inert atmosphere using a dual vacuum/nitrogen line and standard Schlenk-line techniques or in a glove box filled with argon. Ethylene, propylene and nitrogen were purified by passage over columns of $\mathrm{CaCl}_{2}$ and molecular sieves; oxygen was removed by fluxing the gases through BTS catalysts. Before being used in polymerization, the required amount of propylene was condensed into a $25 \mathrm{~mL}$ Schlenk flask kept in liquid nitrogen, then toluene was added and the stabilized propylene solution was brought to room temperature. Toluene (Aldrich, $\geq 99.7 \%$ ) was refluxed over $\mathrm{Na}$ for $8 \mathrm{~h}$, and then distilled and stored over molecular sieves. Dichloromethane (Aldrich, $\geq 99.8 \%$ ) was dried by stirring over $\mathrm{CaH}_{2}$ in inhert 
atmosphere for $8 \mathrm{~h}$, distilled, and stored over $5 \AA$ molecular sieves away from bright light. Ethyltrichloroacetate (ETA, Aldrich, 97\%) was dried by stirring over $\mathrm{CaH}_{2}$ for about $4 \mathrm{~h}$, and then distilled under reduced pressure. $\mathrm{Et}_{2} \mathrm{AlCl}$ (Aldrich) was used as received. $\mathrm{ENB}$ (Aldrich, mixture of endo and exo, 99\% pure), 1-hexene (Aldrich, 97\% pure), and 1-octene (Aldrich, 98\% pure) were dried by stirring over $\mathrm{CaH}_{2}$ for about $4 \mathrm{~h}$, then distilled under reduced pressure and, finally, stored under dry nitrogen and kept at $-30{ }^{\circ} \mathrm{C}$. The synthesis of imido $\mathrm{V}(\mathrm{IV})$ complexes, hereinafter referred as 1a, $\mathbf{2 a}$ and $\mathbf{2 b}$, is reported in our previous work. ${ }^{35,36}$

Polymerization Experiment. Polymerizations were carried out in a $100 \mathrm{~mL}$ roundbottomed Schlenk flask containing a stirring bar. Prior to starting polymerization, the reactor was heated to $110{ }^{\circ} \mathrm{C}$ under vacuum for $1 \mathrm{~h}$, and backfilled with nitrogen. The typical reaction procedure for ethylene/propylene/ENB terpolymerization is as follows. Toluene, the appropriate amount of propylene (as a toluene solution), ENB, ETA (10 equiv. to V) and $\mathrm{Et}_{2} \mathrm{AlCl}$ (500 equiv. to V) were added into the round-bottomed Schlenk flask equipped with a magnetic stirring at room temperature. The solution was quickly degassed and ethylene was added until saturation. The polymerization was started by adding a dichloromethane solution $\left(2 \mathrm{mg} \mathrm{mL}^{-1}\right.$, toluene for $\left.\mathbf{2 a}\right)$ of the vanadium complex via syringe under continuous flow of ethylene. The polymerizations were stopped with methanol containing a small amount of hydrochloric acid; the precipitated polymers were collected by filtration, repeatedly washed with fresh methanol, and finally dried in vacuum at room temperature to constant weight. To test if the resultant terpolymers, particularly those obtained by keeping the comonomer conversion at high level (>5\%), contain high molecular weight PE and cross-linked fractions, a series of extractions with boiling solvents was undertaken. Such fractionation takes advantage of the fact that cross-linked fractions are insoluble in most solvents, and of the tendency of high molecular weight PE to be insoluble in aliphatic solvents, where the target terpolymer is soluble. Neither trace of PE nor of cross-linked fraction was found. This will be relevant in the following, when some hypothesis concerning the time drift in composition will be presented. 
Characterization. NMR spectra of the obtained polymers were recorded on a Bruker NMR advance 400 Spectrometer operating at $400 \mathrm{MHz}\left({ }^{1} \mathrm{H}\right)$ and $100.58 \mathrm{MHz}\left({ }^{13} \mathrm{C}\right)$ working in the PFT mode at $103{ }^{\circ} \mathrm{C}$. The experiments were performed with $10 \mathrm{~mm}$ probe in $\mathrm{C}_{2} \mathrm{D}_{2} \mathrm{Cl}_{4}$ and referred to hexamethyldisiloxane (HMDS) as internal standard. The NMR peak assignment was made according to the literature. ${ }^{37,38}$ As an example, ${ }^{1} \mathrm{H}$ and ${ }^{13} \mathrm{C}$ NMR spectra of sample 3 are reported in Figure S1 and S2, respectively. The content of incorporated comonomers in the terpolymers, and the comonomer conversion were calculated via ${ }^{1} \mathrm{H}$ NMR according to the equations reported in the Supporting Information.

The molecular weight average $\left(M_{\mathrm{w}}\right)$ and the molecular weight distribution $\left(M_{\mathrm{w}} / M_{\mathrm{n}}\right)$ were obtained by a high temperature Waters GPCV2000 size exclusion chromatography (SEC) system equipped with a refractometer detector. The experimental conditions consisted of three PL Gel Olexis columns, ortho-dichlorobenzene as the mobile phase, $0.8 \mathrm{~mL} \mathrm{~min}{ }^{-1}$ flow rate, and $145{ }^{\circ} \mathrm{C}$ temperature. The calibration of the SEC system was constructed using eighteen narrow $M_{\mathrm{w}} / M_{\mathrm{n}}$ poly(styrene) standards with $M_{\mathrm{w}}$ ranging from 162 to $5.6 \times 10^{6} \mathrm{~g} \mathrm{~mol}^{-1}$. For SEC analysis, about 12 mg of polymer was dissolved in $5 \mathrm{~mL}$ of ortho-dichlorobenzene with $0.05 \%$ of BHT as antioxidant.

Differential scanning calorimetry (DSC) scans were carried out on a Perkin-Elmer DSC 8000 instrument equipped with a liquid subambient device under nitrogen atmosphere. The sample, typically $5 \mathrm{mg}$, was placed in a sealed aluminum pan, and the measurement was carried out from 70 to $130{ }^{\circ} \mathrm{C}$ using heating and cooling rate of $20{ }^{\circ} \mathrm{C} \mathrm{min}-1$. The glass transition temperature $\left(T_{\mathrm{g}}\right)$ and the melting temperature $\left(T_{\mathrm{m}}\right)$ were recorded during the second heating. Thermogravimetric analysis (TGA) was performed on a Perkin-Elmer TGA-7 instrument under a nitrogen atmosphere. Before performing the TGA run, the sample $(2.5 \mathrm{mg})$ was held at $50{ }^{\circ} \mathrm{C}$ for $30 \mathrm{~min}$; the scan was carried out from 50 to $750{ }^{\circ} \mathrm{C}$ at a heating rate of $20^{\circ} \mathrm{C} \mathrm{min}^{-1}$.

The materials for the mechanical characterization were molded in a press at $80-120{ }^{\circ} \mathrm{C}$, and 50 bar for $5 \mathrm{~min}$, then the press plates were cooled to $20^{\circ} \mathrm{C} \mathrm{min}^{-1}$ to room temperature. Films with a thickness of about $150 \mu \mathrm{m}$ were produced. Tensile dog-bone-shaped specimens (length overall 75 
$\mathrm{mm}$, gauge length $25 \mathrm{~mm}$, and width of narrow section $4 \mathrm{~mm}$ ) were analyzed at $20^{\circ} \mathrm{C}$ using a Zwick Roell ProLine Z010 mechanical tester equipped with a XforceP (50 N) load cell at a constant crosshead rate of $15 \mathrm{~mm} \mathrm{~min}^{\mathrm{t}}$. In the hysteresis experiments performed at the fixed strain of $300 \%$ (cyclic test 1) or a gradually increased strain between 30 and $1460 \%$ (cyclic test 2), the specimens were cyclically loaded and unloaded in uniaxial tension. The strain recovery (SR) was calculated as $\mathrm{SR}=100\left(\varepsilon_{\mathrm{a}}-\varepsilon_{\mathrm{r}}\right) / \varepsilon_{\mathrm{a}}$, where $\varepsilon_{\mathrm{a}}$ is the applied strain and $\varepsilon_{\mathrm{r}}$ is the strain in the cycle at zero load after the applied strain. For each material, at least five samples were tested for extension experiments and two samples for strain recovery tests.

Wide angle X-ray scattering (WAXS) data were collected on compression-molded films using the multipurpose diffractometer Empyrean (PANalytical) in the $\theta-\theta$ reflection geometry, with Ni-filtered $\mathrm{CuK}_{\alpha}$ radiation (wavelength $\lambda=0.15418 \mathrm{~nm}$ ). The index of crystallinity $\left(\mathrm{x}_{\mathrm{c}}\right)$ was evaluated from the X-ray powder diffraction profiles by the ratio between the crystalline diffraction area $\left(A_{c}\right)$ and the total area of the diffraction profile $\left(A_{t}\right), x_{c}=A_{c} / A_{t}$. The crystalline diffraction area was obtained from the total area of the diffraction profile by subtracting the amorphous halo. The diffraction profiles of the amorphous phase of samples were obtained from the X-ray diffraction profile of the amorphous sample 7 obtained by compression molding. In fact, this sample do not crystallize by cooling the melt to room temperature and amorphous film is obtained by compression molding. Small angle X-ray scattering (SAXS) data were collected on compression molded films under vacuum using the apparatus "SAXSess" (Anton Paar KG, Graz, Austria), in the slit collimation configuration, with $\mathrm{CuK}_{\alpha}$ radiation (wavelength $\lambda=1.5418 \AA$ ). The intensity was recorded on an imaging plate and processed with a digital imaging reader (Perkin-Elmer Cyclone Plus Phosphor Imager) in the $q$ range $0.09-3 \mathrm{~nm}^{-1}$, with $\mathrm{q}=4 \pi \sin \theta / \lambda, 2 \theta$ being the scattering angle. After subtraction for dark current, the empty sample holder, and a constant background due to thermal density fluctuations, the slit smeared data were deconvolved with the primary beam intensity distribution using the SAXSquant 2.0 software to obtain the corresponding pinhole scattering (desmeared) intensity distribution. 
Atomic force microscopy (AFM) measurements were carried on a Bruker Multimode 8, in tapping mode, using a silicon cantilever RTESTPA-300 tip with radius of about $8 \mathrm{~nm}$, at resonance frequency and force constant in the range $200-400 \mathrm{kHz}$ and $40 \mathrm{~N} \mathrm{~m}^{-1}$, respectively. For AFM measurements, polymer films (with a thickness of 50-100 nm) have been prepared via drop casting from $0.05 \mathrm{wt} \% p$-xylene solution on a glass-slide. Thus, the obtained films were heated at temperature $20-30{ }^{\circ} \mathrm{C}$ higher than the melting temperature of the sample at $40{ }^{\circ} \mathrm{C} \mathrm{min}-1$ and held 5 minutes, then cooled at $2.5{ }^{\circ} \mathrm{C} \min ^{-1}$ to $-50{ }^{\circ} \mathrm{C}$ and re-heated to room temperature (for AFM imaging) with a rate of $50{ }^{\circ} \mathrm{C} \min ^{-1}$ in a Linkam hot-stage. $\mathrm{AFM}$ images were processed with Gwyddion software.

\section{RESULTS AND DISCUSSION}

\section{Catalytic Utility}

Recently, we demonstrated that imido V(IV) complexes are efficient precatalysts in the copolymerization of ethylene with $\alpha$-olefins, ${ }^{35}$ and cyclic olefins. ${ }^{36}$ Herein, the catalytic utility of some known imido V(IV) complexes has been investigated in the terpolymerization of ethylene with propylene and ENB. Two of the selected complexes have the tert-butyl imido substituent but differ in the nature of coligand, i.e., pyridine (Py) vs dimethylamine $\left(\mathrm{NHMe}_{2}\right)$. They are $\mathrm{V}\left(=\mathrm{N}^{t} \mathrm{Bu}\right) \mathrm{Cl}_{2}\left(\mathrm{NHMe}_{2}\right)_{2}(\mathbf{1 a})$, and $\mathrm{V}\left(=\mathrm{N}^{t} \mathrm{Bu}\right) \mathrm{Cl}_{2}(\mathrm{Py})_{3}(\mathbf{2 a})$. The third one has the pyridine coligand as

2a but a different imido substituent, i.e., $\mathrm{V}\left(=\mathrm{NCPh}_{3}\right) \mathrm{Cl}_{2}(\mathrm{Py})_{3}(\mathbf{2 b})($ Chart 1).

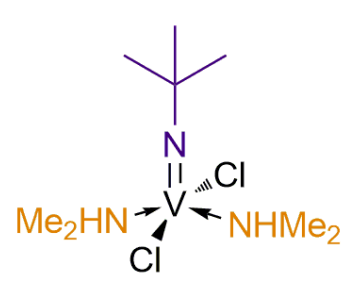

1a

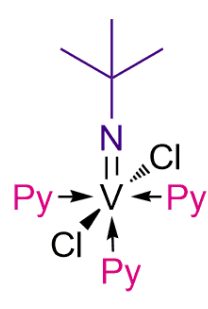

2a

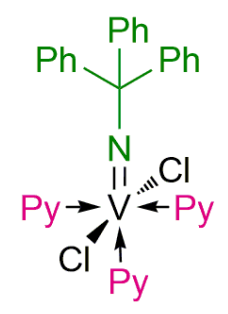

$2 b$

Chart 1. Imido vanadium(IV) complexes used in this work.

The polymerizations were carried out in a semi-batch mode, at an ethylene pressure of 1 atm, 
room temperature, and by using $2.5 \mu \mathrm{mol}$ of vanadium precursor to easily maintain the temperature throughout the polymerization without cooling in the early stages (Scheme 1). We expected these complexes to be successfully activated by $\mathrm{Et}_{2} \mathrm{AlCl}$ (500 equiv. to $\mathrm{V}$ ) and in the presence of ETA (10 equiv. to V), which acts as reoxidant. ${ }^{39}$ The ethylene gaseous monomer was replenished by maintaining a constant gas pressure during the reaction timecourse, while all the liquid comonomers were placed in the reactor at the beginning. Neither homopolymerization of propylene and ENB nor copolymerization of propylene with ENB was observed under the conditions employed. A first screening was performed at $\mathrm{P} / \mathrm{E} / \mathrm{ENB}=4 / 1 / 0.5$. The results are summarized in Table 1.

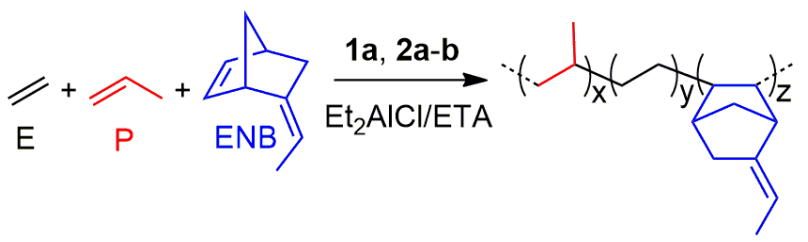

Scheme 1. Terpolymerization of ethylene (E) with propylene (P) and ENB.

Table 1. Terpolymerization of ethylene with propylene and ENB by $\mathbf{1 a}, \mathbf{2 a}-\mathbf{b}$ in combination with $\mathrm{Et}_{2} \mathrm{AlCl}$ and $\mathrm{ETA}{ }^{a}$

\begin{tabular}{|c|c|c|c|c|c|c|c|c|c|c|}
\hline \multirow[t]{2}{*}{ entry } & \multirow[t]{2}{*}{ cat } & \multirow{2}{*}{$\begin{array}{l}\text { yield } \\
(\mathrm{mg})\end{array}$} & \multirow[t]{2}{*}{ Activity $^{b}$} & \multicolumn{3}{|c|}{$\begin{array}{c}\text { terpolymer } \\
\text { composition }(\mathrm{mol} \%)^{c}\end{array}$} & \multicolumn{2}{|c|}{$\begin{array}{c}\begin{array}{c}(\text { co)monomer } \\
\text { conversion }(\%)^{d}\end{array} \\
\end{array}$} & \multirow{2}{*}{$\begin{array}{l}M_{\mathrm{w}}{ }^{e} \\
\times 10^{3}\end{array}$} & \multirow[t]{2}{*}{$M_{\mathrm{w}} / M_{\mathrm{n}}$} \\
\hline & & & & $\mathbf{E}$ & $\mathbf{P}$ & ENB & $\mathbf{P}$ & ENB & & \\
\hline 1 & 1a & 72 & 433 & 92.5 & 2.5 & 5.0 & 0.2 & 3.0 & 193 & 1.9 \\
\hline 2 & $2 a$ & 263 & 1578 & 83.6 & 6.4 & 10.0 & 1.6 & 19.3 & 143 & 2.0 \\
\hline 3 & $2 b$ & 501 & 3006 & 80.3 & 6.5 & 13.2 & 2.8 & 44.9 & 112 & 1.9 \\
\hline
\end{tabular}

${ }^{a}$ polymerization conditions: ethylene pressure, $1.01 \mathrm{bar}$; total volume, $50 \mathrm{~mL}$ (toluene); $\mathrm{V}$ complex, $2.5 \mu \mathrm{mol} ; \mathrm{Al} / \mathrm{V}=500 ; \mathrm{ETA} / \mathrm{V}=$ 10; temperature, $20{ }^{\circ} \mathrm{C}$; time, $2 \mathrm{~min}$; P/E/ENB feed ratio $=4 / 1 / 0.5(\mathrm{~mol} / \mathrm{mol})$ in liquid phase; ${ }^{b}$ activity in $\mathrm{kg}_{\mathrm{pol}} \times\left(\mathrm{mol}_{\mathrm{V}} \times \mathrm{h}\right)^{-1} ;{ }^{c}$ determined by NMR; ${ }^{d}$ the comonomer conversion was calculated by combining the NMR data, comonomer feed, and weight of the obtained terpolymer as reported in the supporting information; ${ }^{e}$ determined by SEC.

Except the bis-dimethylamine $\mathbf{1 a}, \mathbf{2 a}$ and $\mathbf{2 b}$ were instantaneously activated, and the terpolymerization proceeds at significant rates, affording high-ethylene ( $\mathrm{E}>80 \mathrm{~mol} \%$ ), high molecular weight EPDMs with unimodal and reasonably narrow molecular weight distribution $\left(M_{\mathrm{w}} / M_{\mathrm{n}}=1.9-2.0\right.$, Figure S3). The side double bond of ENB did not partecipate in the terpolymerization, and each link of ENB in the terpolymer contains an ethylidene group (Scheme 1). ${ }^{1} \mathrm{H}$ NMR spectra show signals in the region from 5.0 to $5.4 \mathrm{ppm}$, assigned to the ethylidene 
group, while the lack of signals at about $6.0 \mathrm{ppm}$ confirms that the coordination/insertion of ENB occurs only through the intracyclic norbornene double bond (Figure S1). ${ }^{36}$ The thermal stability of the terpolymers was investigated by TGA under an inert atmosphere. As an example, the thermogram of sample $\mathbf{2}$ is reported in Figure S4. All the terpolymers were found to be thermally stable, with the initial degradation temperature corresponding to $1 \%$ mass loss being higher than $310^{\circ} \mathrm{C}$. Their thermal stability is sufficiently enough for processing them at temperature higher than their melting temperature.

Changes in the imido substituent and coligand substitution brought significant effect on the polymerization initiation rate, and hence on the productivity. As abovementioned, except 1a, 2a and 2b were instantaneously activated. This result is consistent with our previous results for the copolymerization of ethylene with propylene. ${ }^{35}$ One plausible explanation for the low initiation rate of 1a would be that $\mathrm{NHMe}_{2}$ remains closer to the active center than the pyridine due to its stronger Lewis base character, thus limiting the approach of the (co)monomers. The involvement of a deleterious interaction between the amine and the aluminum alkyl, leading to the deprotonation of dimethylamine or preventing catalyst formation in terms of efficient alkylation may also account for. $^{40}$

All the investigated catalysts show a preference for incorporating ENB to propylene, which is consistent with the fact that they are more active in the ethylene copolymerization with cyclic olefins, ${ }^{36}$ than with $\alpha$-olefins. ${ }^{35}$ The comonomer incorporation was affected by the ligand set: it increases in the order $1 \mathbf{a}(\mathrm{P}=2.5 \mathrm{~mol} \% ; \mathrm{ENB}=5.0 \mathrm{~mol} \%) \ll \mathbf{2 a}(\mathrm{P}=6.4 \mathrm{~mol} \% ; \mathrm{ENB}=10.0 \mathrm{~mol} \%)$ $<2 \mathbf{b}(\mathrm{P}=6.5 \mathrm{~mol} \%$; ENB $=13.2 \mathrm{~mol} \%)$, the effect of coligand being dominant over the effect of imido substituents.

Comonomer conversion beyond 5\%, and even up to about $45 \%$ in the case of ENB (Table 1, entry 3), do not allow the applicability of standard theoretical tool of homogeneous Markov chain to establish precise comonomer positioning and calculation of reactivity ratios. Indeed, the applicability of this tool would require an almost constant comonomer feed ratio that in our case 
would have meant stopping immediately the polymerization at low comonomer conversion. At this time, only qualitative information can be drawn by ${ }^{13} \mathrm{C}$ NMR spectra. As an example, the ${ }^{13} \mathrm{C}$ NMR spectra of sample 3 is shown in Figure S4. The dominant signals are those corresponding to isolated and alternating propylene and ENB units spanning long methylene segments, while the lack of signals due to $\mathrm{P}-\mathrm{ENB}$ sequences may account for the observation that the copolymerization of propylene with ENB did not occur.

It is worth of note that the high comonomer consumption (from which the concentration is allowed to deplete by incorporation into the polymer chains), while ethylene is fed continuously, causes strong variation in the instantaneous comonomer feed composition, thus altering the composition of the terpolymer over the period of conversion. The comonomer feed changes in composition as one of the comonomer preferentially enter the terpolymer chain, thus resulting in a composition drift towards the less reactive comonomer over time. This drift in composition implies the formation of heterogeneous terpolymers with a broad chemical composition distribution (CCD). At least in principle, the chains formed at the reaction start, when the comonomer concentration is at the maximum, should have the highest fraction of comonomers. As propylene and ENB are consumed, both the two comonomers will enter the chain occasionally and with decreasing frequency. At the end of the terpolymerization, with very little comonomer left in the reactor flask, the formed chains should have the highest fraction of ethylene. ${ }^{41}$ If the comonomer feed composition changes significantly, then the properties of the resultant EPDMs should become conversion dependent. To test this hypothesis, additional tests were carried out increasing the polymerization time, and at various comonomer feedstock ratio. It is expected that the conditions for an accentuated composition drift could be created.

\section{Effect of Composition Drift on EPDM Properties}

While homogeneous copolymers are desirable for certain applications, such as optical use, it is known that heterogeneous copolymers are effective in reinforcing polymer-polymer interfaces, and composition drift may account for the effectiveness of such polymers as compatibilizer. ${ }^{42}$ 
However, at least to the best of our knowledge, studies about the effect of CCD on the properties of EPDMs are scarce. Only recently, scientists at the Sumimoto Chemical Co. have shown that superior EPDMs in terms of weather resistance can be obtained by making the CCD narrow using modified vanadium catalysts. ${ }^{43}$

\section{The Case of Complex 1a}

The terpolymerization behavior of $\mathbf{1 a} / \mathrm{Et}_{2} \mathrm{AlCl} / \mathrm{ETA}$ was investigated for a reaction time between 2 and $6 \mathrm{~min}$ in steps of 1 or $2 \mathrm{~min}$, and at $\mathrm{P} / \mathrm{E} / \mathrm{ENB}=4 / 1 / 0.5$. Polymerizations longer than 6 min were not performed to maintain physical homogeneous conditions and to avoid side reactions caused by gel effect and high mixture viscosities. Details of polymerization conditions and results are summarized in Table 2.

Table 2. Terpolymerization of ethylene with propylene and ENB by $\mathbf{1 a} / \mathrm{Et}_{2} \mathrm{AlCl} / \mathrm{ETA}$ at different polymerization time. ${ }^{a}$

\begin{tabular}{|c|c|c|c|c|c|c|c|c|c|c|c|}
\hline \multirow[t]{2}{*}{ entry } & \multirow{2}{*}{$\begin{array}{c}\text { time } \\
(\min )\end{array}$} & \multirow{2}{*}{$\frac{\text { yield }}{(\mathrm{mg})}$} & \multirow[t]{2}{*}{ activity $^{b}$} & \multicolumn{3}{|c|}{$\begin{array}{c}\text { terpolymer } \\
{\text { composition }(\mathbf{m o l} \%)^{c}}^{c}\end{array}$} & \multicolumn{2}{|c|}{$\begin{array}{c}\begin{array}{c}(\text { co)monomer } \\
\text { conversion }(\%)^{d}\end{array} \\
\end{array}$} & \multirow{2}{*}{$\begin{array}{l}M_{w}{ }^{e} \\
\times 10^{3}\end{array}$} & \multirow{2}{*}{$M_{\mathrm{w}} / M_{\mathbf{n}}{ }^{e}$} & \multirow{2}{*}{$\frac{T_{g}\left(T_{m}\right)}{\left({ }^{\circ} \mathbf{C}\right)}$} \\
\hline & & & & $\mathbf{E}$ & $\mathbf{P}$ & ENB & $\mathbf{P}$ & ENB & & & \\
\hline $\mathbf{1}^{g}$ & 2 & 72 & 433 & 92.5 & 2.5 & 5.0 & 0.2 & 3.0 & 193 & 1.9 & $-5(42)$ \\
\hline 4 & 3 & 170 & 680 & 88.0 & 3.1 & 8.9 & 0.5 & 11.5 & 197 & 2.0 & $-4(44)$ \\
\hline 5 & 5 & 474 & 1139 & 85.8 & 4.2 & 9.9 & 1.8 & 34.5 & 136 & 1.9 & $-4(46)$ \\
\hline 6 & 6 & 721 & 1442 & 87.1 & 3.3 & 9.6 & 2.2 & 51.7 & 100 & 2.3 & $-3(47)$ \\
\hline
\end{tabular}

\footnotetext{
${ }^{a}$ polymerization conditions: ethylene pressure, $1.01 \mathrm{bar}$; total volume, $50 \mathrm{~mL}$ (toluene); $\mathrm{V}$ complex, $2.5 \mu \mathrm{mol} ; \mathrm{Al} / \mathrm{V}=500 ; \mathrm{ETA} / \mathrm{V}=$ 10; temperature, $20{ }^{\circ} \mathrm{C} ; \mathrm{P} / \mathrm{E} / \mathrm{ENB}$ feed ratio $=4 / 1 / 0.5(\mathrm{~mol} / \mathrm{mol})$ in liquid phase; ${ }^{b}$ activity in $\mathrm{kg}_{\mathrm{pol}} \times\left(\mathrm{mol}_{\mathrm{V}} \times \mathrm{h}\right)^{-1} ;{ }^{c}$ determined by NMR;

${ }^{d}$ the comonomer conversion was calculated by combining the NMR data, comonomer feed, and weight of the obtained terpolymer as reported in the supporting information; ${ }^{e}$ determined by SEC; ${ }^{f}$ determined by DSC (second heating); ${ }^{g}$ first reported in Table 1.
}

All the obtained terpolymers have high molecular weight $\left(100<M_{\mathrm{w}} \times 10^{3} \mathrm{~g} \mathrm{~mol}^{-1}<197\right)$, and relatively narrow molecular weight distribution $\left(1.9<M_{\mathrm{w}} / M_{\mathrm{n}}<2.3\right)$. As shown in Figure 1 A, both the yield and the activity linearly increased with the polymerization time, meaning also a sufficient stability of 1a over time. Figure 1B shows that there is a continuous increase in the comonomer conversion over time, and that ENB always preferentially incorporates into the terpolymer by a higher rate than propylene, reaching a conversion of $51.7 \%$ vs $2.2 \%$ (entry $\mathbf{6}$ ). The comonomers are consumed at different rates in the terpolymerizations, and consequently the 
comonomer feed composition changes in the course of the reaction. As chains are created and terminated continuously in a chain-growth polymerization, it is expected that the variation in comonomer feed ratio results in fluctuations in the composition of the terpolymer with conversion, as shown in Table 2, and broad CCD. The content of ENB in the terpolymer increases quickly up to $11.5 \%$ of conversion, while for the next two minutes of reaction the increase of ENB incorporated in the terpolymer is much slower. This behavior is consistent with a rapid exhaustion of ENB at the beginning of the terpolymerization.
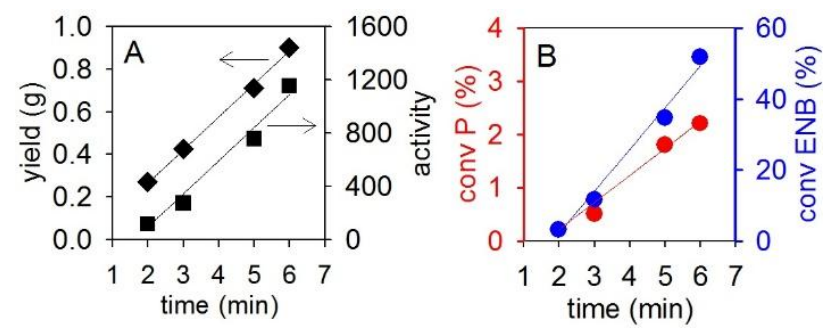

Figure 1. (A) Plot of yield and activity in $\mathrm{kg}_{\mathrm{pol}} \times\left(\operatorname{mol}_{\mathrm{v}} \times \mathrm{h}\right)^{-1}$ vs reaction time, (B) Plot of propylene and ENB conversion vs reaction time.

However, since 1a has a low initiation rate, it can be inferred that a more pronounced composition drift likely occurs for the experiment 6 min long (entry 6). At this time, the ethylene content increases to $87.1 \mathrm{~mol} \%$ with respect to the same data of $85.8 \mathrm{~mol} \%$ for the experiment 5 min long. This increase in the ethylene content together with the increase in the comonomer consumption (Figure 1B) indicates that, when the reaction bath is severely depauperated in the comonomers, and most of ENB is consumed, the rate of ethylene homopolymerization is accelerated with respect to the (co)polymerization rate, thus increasing the chance of forming longer ethylene sequences. Obviously, these data do not give a clear picture on the instantaneous composition as a function of terpolymer chain length and comonomer conversion. Such a description is highly challenging in ternary copolymerizations, and would require laborious polymer fractionation and multi-sample special analysis, which are not feasible in our laboratory. At present, the boiling solvent fractionation does not allow us to have an unambiguous explanation and 
photograph of the $\mathrm{CCD}$ of these terpolymers due to the failure of the fractionation to isolate insoluble fractions. It may likely due to the fact that the resultant EPDMs are unusual in that they are reasonably homogeneous in terms of $M_{\mathrm{w}} / M_{\mathrm{n}}$ but have broad CCD as also revealed by the broad melting transitions characteristic of all the synthesized EPDMs in this study. In addition, the fact that long ethylene sequences are chemically attached to the amorphous chain segments may also account for.

DSC heating curves of non-isothermal crystallized terpolymers are shown in Figure S5. Glass transition event at low temperature, followed by cold crystallization events and broad melting endotherms at higher temperature can be observed during second heating scans. The glass transition temperature $\left(T_{\mathrm{g}}\right)$ ranges from -5 to $-3{ }^{\circ} \mathrm{C}$, while the melting peak temperature $\left(T_{\mathrm{m}}\right)$ goes from 42 to $48^{\circ} \mathrm{C}$.

These data do not appear to be closely related to the terpolymer composition, and it could be inferred that composition drift may have an unpredictable effect on thermal properties. Indeed, random (co)polymers with an ethylene content as high as $85 \mathrm{~mol} \%$ usually are semicrystalline materials with $T_{\mathrm{m}}$ higher than those of terpolymers under investigation. ${ }^{44}$ At least in principle, the presence of ENB-rich segments and chains, formed at the beginning of the reaction, may hinders the crystallization of those chains having longer methylene sequences and contribute to lowering the $T_{\mathrm{m}}$. Besides, it is worth of note that $T_{\mathrm{g}}$ and $T_{\mathrm{m}}$ of these terpolymers are comparable. Altogether, the results suggest that the time drift in composition is relatively small, consistent with the low polymerization initiation rate exhibited by $\mathbf{1 a}$.

Preliminary investigation on the mechanical behavior of sample $\mathbf{5}$ and $\mathbf{6}$ was carried out at room temperature by uniaxial stretching until failure. The stress--strain curves are shown in Figure 2. The tensile properties are listed in Table 3. 

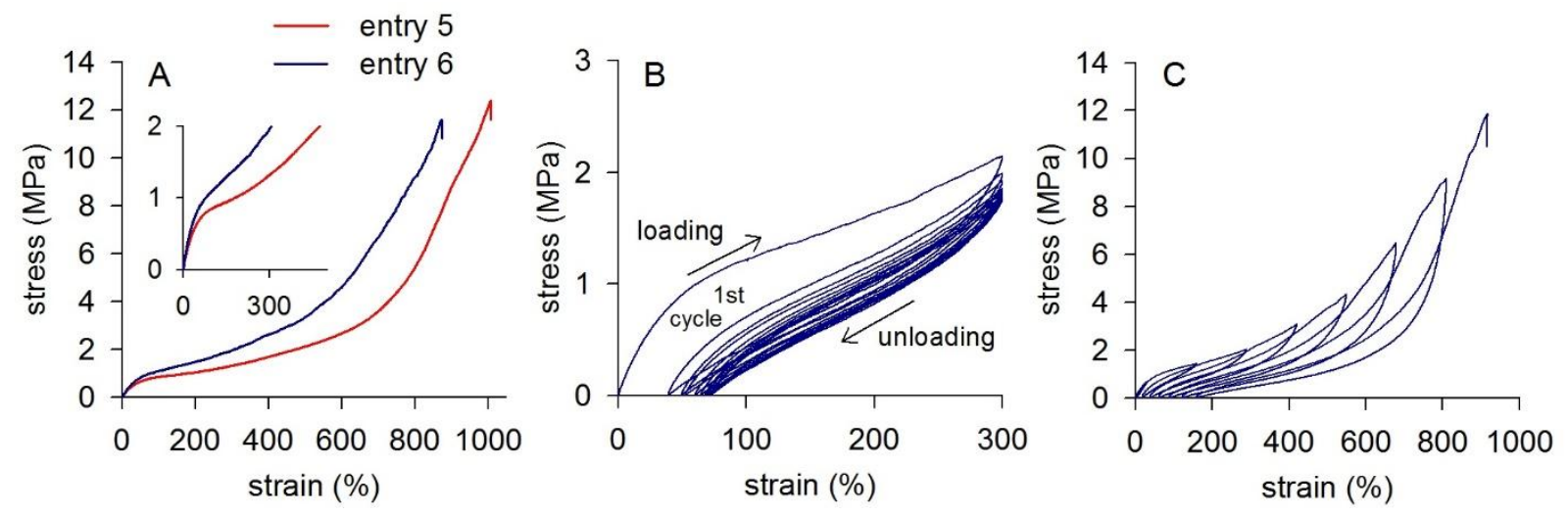

Figure 2. (A) Stress-strain curves of sample 5 and 6, (B) stress-strain curve of sample $\mathbf{6}$ in the hysteresis experiments for a strain of $300 \%$, and (C) stress-strain curve of sample $\mathbf{6}$ during step cycle tensile deformation at different strain.

Table 3. Mechanical properties of EPDMs obtained with $1 \mathrm{a} / \mathrm{Et}_{2} \mathrm{AlCl} / \mathrm{ETA}$.

\begin{tabular}{|c|c|c|c|c|c|c|c|}
\hline \multirow{2}{*}{ entry } & \multirow{2}{*}{$\begin{array}{c}E^{a} \\
(\mathrm{MPa})\end{array}$} & \multirow{2}{*}{$\begin{array}{c}\sigma^{b} \\
(\mathbf{M P a})\end{array}$} & \multirow{2}{*}{$\begin{array}{c}\varepsilon^{c} \\
(\%) \\
\end{array}$} & \multicolumn{2}{|c|}{ cyclic test 1} & \multicolumn{2}{|c|}{ cyclic test 2} \\
\hline & & & & $\mathbf{S R}_{\mathrm{I}}^{d}$ & $\mathbf{S R}_{\mathbf{X}}{ }^{e}$ & $\mathbf{S R}_{\mathbf{4 2 0} \%}{ }^{f}$ & $\mathbf{S R}_{\mathbf{8 1 0} \%^{g}}{ }^{g}$ \\
\hline 5 & $2.4 \pm 0.1$ & $12.2 \pm 1.1$ & $968 \pm 75$ & 84 & 71 & 83 & 81 \\
\hline 6 & $3.0 \pm 0.1$ & $11.9 \pm 0.6$ & $878 \pm 55$ & 87 & 76 & 85 & 81 \\
\hline
\end{tabular}

$\overline{{ }^{a}}$ Young's modulus; ${ }^{b}$ ultimate tensile strength; ${ }^{c}$ elongation at break; ${ }^{d}$ strain recovery measured after the first step in a step cycle test type at $300 \%$ strain; ${ }^{e}$ strain recovery measured after the last step in a step cycle test type at $300 \%$ strain; ${ }^{f}$ strain recovery measured after the strain at $420 \%$ in a step cycle test type at increasing strains; ${ }^{g}$ strain recovery measured after the strain at $810 \%$ in a step cycle test type at increasing strains.

Both the samples show stress-strain curves with typical features of elastomers, i.e., low Young's modulus, uniform deformation to high strain, a fracture strain higher than $800 \%$, and strain hardening at the late stage of deformation. The low values of Young's modulus and the high deformability is associated to the fact that both samples are amorphous in the unstretched state, as demonstrated by WAXS of compression molded samples (Figure S6A), and SAXS patterns (Figure S6B), which confirm the absence of lamellar-stacks or phase heterogeneities. It is worth of note that in these crystallization conditions, where the samples are compression molded from the melt and cooled down to room temperature, crystallization does not occur. Strain hardening at the late stage of deformation may be likely associated with crystallization induced by stretching. Crystallization of ethylene sequences may occur during deformation. Small crystals can form upon 
stretching, acting as physical knots in the elastomeric network, resulting in increase of tensile strength of the rubber. It is known that elastomers can experience strain-induced crystallization after deformation. ${ }^{45-48}$ Some changes in the onset of strain hardening and yield stress are observed. Sample $\mathbf{6}$ has a significantly higher yield stress than sample 5 (see the inset of Figure 2A) in spite of the fact that both are amourphous with a comparable composition. It is worth of note that both samples present a diffuse yielding around $40-60 \%$ of deformation. The presence of broad yield maximum or its complete absence is a feature common to all the samples included in this study. At deformation higher than $100 \%$, it likely that both samples start to experience progressively strain-induced crystallization that is enhanced in sample 6. In fact, sample $\mathbf{6}$ shows higher stress values at any strain compared to those of sample 5. The higher degree of composition drift, and consequent higher heterogeneity, for $\mathbf{6}$ may account for this phenomenon, as also found by Séguéla et al. by comparing a homogeneous ethylene copolymer from metallocene with a heterogeneous one from conventional Ziegler-Natta catalysts. ${ }^{49}$ Furthermore, this behavior is also in agreement with data recently reported by some of us in ref. 48 where is shown that almost amorphous EPDMs experience significant strain-induced crystallization only above a threshold value $(\approx 170 \%)$.

The elasticity of both the samples, i.e., the capability to return to the initial state once the force is removed, was evaluated from step cycle tensile tests. In the first set of experiments, the samples were cyclically loaded and unloaded ten times to $300 \%$ strain, and the $\%$ recovery in specimen length was measured after removal of the strain for each cycle. As representative, the cyclic curve of sample $\mathbf{6}$ is shown in Figure 2B. The first cycle results in the most significant amount of permanent deformation, followed by minimal increase in the unrecovered strain on subsequent cycles. The recovery strain after the first load cycle is $84 \%$ for sample $\mathbf{5}$ and $87 \%$ for sample 6, while of $71 \%$ and $76 \%$ after the last load cycle, respectively (Table 3 ). In the second set of hysteresis experiments, the samples were extended step by step up to different strains (Figure 2C). The hysteresis loop enlarged only gradually as the applied strain increased, both samples giving remarkable and almost stable strain recovery in the range from 85 to $81 \%$ when the applied 
strain goes from 420 to $810 \%$, respectively (Table 3). The elastic behavior is slightly improved in sample 6 that, presumably, presents a more effective crystalline network that acts as physical nodes during stretching and successive release of the tension.

\section{The Case of Complex 2a}

The terpolymerization behavior of $\mathbf{2} \mathbf{a} / \mathrm{Et}_{2} \mathrm{AlCl} / \mathrm{ETA}$ was investigated for a reaction time between 2 and $6 \mathrm{~min}$ in steps of $2 \mathrm{~min}$ at $\mathrm{P} / \mathrm{E} / \mathrm{ENB}=4 / 1 / 0.5$, and at $\mathrm{ENB}$ concentration in the feed as low as $0.035 \mathrm{~mol} \mathrm{~L}^{-1}(\mathrm{P} / \mathrm{E} / \mathrm{ENB}=4 / 1 / 0.25)$ for a time of 2 and $4 \mathrm{~min}$. Due to very high polymerization initiation rate exhibited by $\mathbf{2 a}$, particularly when a low amount of ENB was used, polymerization longer than $4 \mathrm{~min}$ were not performed at $\mathrm{P} / \mathrm{E} / \mathrm{ENB}=4 / 1 / 0.25$ to maintain physical homogeneous conditions and to avoid side reactions caused by gel effect and high mixture viscosities. Details of polymerization conditions and results are summarized in Table 4.

Table 4. Terpolymerization of ethylene with propylene and ENB by $\mathbf{2 a} / \mathrm{Et}_{2} \mathrm{AlCl} / \mathrm{ETA}^{a}$

\begin{tabular}{|c|c|c|c|c|c|c|c|c|c|c|c|c|}
\hline \multirow{2}{*}{ entry } & \multirow[t]{2}{*}{$\mathbf{P} / \mathbf{E} / \mathbf{E N B}^{b}$} & \multirow{2}{*}{$\begin{array}{c}\text { time } \\
\text { (min) }\end{array}$} & \multirow{2}{*}{$\frac{\text { yield }}{(\mathrm{mg})}$} & \multirow{2}{*}{ activity $^{c}$} & \multicolumn{3}{|c|}{$\begin{array}{c}\text { terpolymer } \\
\text { composition }(\mathrm{mol} \%)^{d}\end{array}$} & \multicolumn{2}{|c|}{$\begin{array}{c}\text { (co)monomer } \\
\text { conversion }(\%)^{e}\end{array}$} & \multirow{2}{*}{$\begin{array}{l}M_{\mathrm{w}}^{f} \\
\times \mathbf{1 0}^{3}\end{array}$} & \multirow{2}{*}{$\boldsymbol{M}_{\mathbf{w}} / \boldsymbol{M}_{\mathbf{n}}^{f}$} & \multirow{2}{*}{$\frac{T_{g}\left(T_{m}\right)^{g}}{\left({ }^{\circ} \mathbf{C}\right)}$} \\
\hline & & & & & $\mathbf{E}$ & $\mathbf{P}$ & ENB & $\mathbf{P}$ & ENB & & & \\
\hline $2^{h}$ & 4/1/0.5 & 2 & 263 & 1578 & 83.6 & 6.4 & 10.0 & 1.6 & 19.3 & 143 & 2.0 & $-6(40)$ \\
\hline 7 & 4/1/0.5 & 4 & 516 & 1548 & 76.8 & 11.4 & 11.8 & 5.1 & 42.0 & 96 & 2.1 & -7 \\
\hline 8 & 4/1/0.5 & 6 & 1160 & 2320 & 85.3 & 5.4 & 9.2 & 5.9 & 80.1 & 102 & 2.1 & $-6(69)$ \\
\hline 9 & $4 / 1 / 0.25$ & 2 & 326 & 1956 & 83.7 & 9.9 & 6.4 & 3.2 & 32.9 & 127 & 2.1 & $-18(51)$ \\
\hline 10 & 4/1/0.25 & 4 & 765 & 2295 & 89.2 & 4.7 & 6.1 & 3.7 & 76.1 & 109 & 2.4 & $-9(68)$ \\
\hline
\end{tabular}

${ }^{a}$ polymerization conditions: ethylene pressure, $1.01 \mathrm{bar}$; total volume, $50 \mathrm{~mL}$ (toluene); $\mathrm{V}$ complex, $2.5 \mu \mathrm{mol} ; \mathrm{Al} / \mathrm{V}=500 ; \mathrm{ETA} / \mathrm{V}=$ 10; temperature, $20{ }^{\circ} \mathrm{C} ;{ }^{b} \mathrm{P} / \mathrm{E} / \mathrm{ENB}$ feed ratio (mol/mol) in liquid phase; ${ }^{c}$ activity in $\mathrm{kg}_{\text {pol }} \times\left(\mathrm{mol}_{\mathrm{V}} \times \mathrm{h}\right)^{-1} ;{ }^{d}$ determined by $\mathrm{NMR}$; ${ }^{e}$ the comonomer conversion was calculated by combining the NMR data, comonomer feed, and weight of the obtained terpolymer as reported in the supporting information; ${ }^{f}$ determined by SEC; ${ }^{g}$ determined by DSC (second heating); ${ }^{h}$ first reported in Table 1.

For the experiments at $\mathrm{P} / \mathrm{E} / \mathrm{ENB}=4 / 1 / 0.5$, when the polymerization was quenched after 2 min (entry 2), a terpolymer with a propylene content of 6.4 mol\% (equivalent to $1.6 \%$ conversion of added propylene) and ENB content of $10.0 \mathrm{~mol} \%$ (equivalent to $19.3 \%$ conversion of added ENB) was obtained. Sample 2 exhibits a $T_{\mathrm{g}}$ of about $-6^{\circ} \mathrm{C}$, a probable cold crystallization, and a melting event with $T_{\mathrm{m}}$ at about $40{ }^{\circ} \mathrm{C}$ (Figure 3 ). When the polymerization time was extended to 4 min 
(entry 7), the yields doubled and the activity remained almost constant: a terpolymer with a propylene content of $11.4 \mathrm{~mol} \%$ (equivalent to $5.1 \%$ conversion of added propylene) and ENB content of $11.8 \mathrm{~mol} \%$ (equivalent to $42.0 \%$ conversion of added ENB) was obtained. Sample 7 shows only a glass transition event with $T_{\mathrm{g}}$ at $-7{ }^{\circ} \mathrm{C}$, while no melting event was observed likely because the sum of propylene and ENB in the terpolymer is more than 20 mol\%, a composition that usually prevents crystallization. ${ }^{50}$ When the polymerization time was extended to 6 min (entry 8), the yield more than doubled, and the activity significantly increased. The increase in activity could be likely because the rate of the homopolymerization of ethylene accelerated with respect to the (co)polymerization rate since the reaction mixture is strongly depauperated in the comonomers (the conversion of ENB reaches $80 \%$ ). At this time, significant composition drift occurs, and the ethylene content in the terpolymer increases from 76.8 to 85.3 mol\%, even though the conversion of the comonomers still grows, the conversion of propylene much less than ENB. Consistent with a more pronounced composition drift, and hence with a formation of longer ethylene sequences, the DSC thermogram of sample $\mathbf{8}$ shows, in addition to the $T_{\mathrm{g}}$ at $-6^{\circ} \mathrm{C}$, a broad and multimodal melting endotherm, the melting point taken at the peak maximum being at about $69{ }^{\circ} \mathrm{C}$ (Figure 3). The broad shape of the melting event could originate from the non-homogeneous distribution of crystallizable units along the polymer chain, and among the polymer chains (i.e., intra- and intermolecular heterogeneity). According to the DSC, the WAXS profile of melt crystallized sample 8 shows the presence of slight crystallinity (4\%) (Figure S7A).

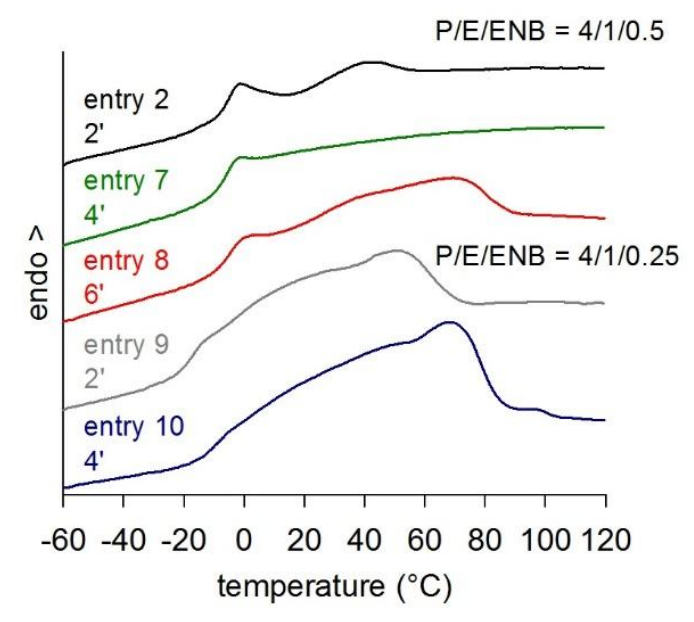


Figure 3. DSC heating scan of E/P/ENB terpolymers obtained by $\mathbf{2 a} / \mathrm{Et}_{2} \mathrm{AlCl} / \mathrm{ETA}$.

Large differences were observed by comparing samples obtained at $\mathrm{P} / \mathrm{E} / \mathrm{ENB}=4 / 1 / 0.5$ with those at $\mathrm{P} / \mathrm{E} / \mathrm{ENB}=4 / 1 / 0.25$ on the same time scale. At $[\mathrm{ENB}]_{0}=0.035 \mathrm{~mol} \mathrm{~L}^{-1}$ (entry $\mathbf{9}$ and 10), the productivities of $\mathbf{2 a}$ were considerably higher compared to the same experiments at $[\mathrm{ENB}]_{0}=$ $0.07 \mathrm{~mol} \mathrm{~L}^{-1}$ (entry 2 and 7). When the polymerization was quenched after 2 min (entry 9), a terpolymer with a propylene content of $9.9 \mathrm{~mol} \%$ (equivalent to $3.2 \%$ conversion of added propylene) and ENB content of 6.4 mol\% (equivalent to $32.9 \%$ conversion of added ENB) was obtained. Sample 9 exhibits a $T_{\mathrm{g}}$ as low as $-18{ }^{\circ} \mathrm{C}$, consistent with the increased propylene content, and a broad melting endotherm with $T_{\mathrm{m}}$ at about $51{ }^{\circ} \mathrm{C}$ (Figure 3). When the polymerization was quenched after 4 min (entry 10), a terpolymer with a propylene content of 4.7 mol\% (equivalent to $3.7 \%$ conversion of added propylene) and ENB content of $6.1 \mathrm{~mol} \%$ (equivalent to $76.1 \%$ conversion of added ENB) was obtained. The fast depletion of comonomers already in the first two minutes of the reaction determines a significant composition drift over time. The content of ethylene increases up to $89.2 \mathrm{~mol} \%$ with respect to the same data of $83.7 \mathrm{~mol} \%$ for the experiment 2 min long. Accordingly, sample $\mathbf{1 0}$ exhibits a broader and multimodal melting endotherm shifted to higher temperature (Figure 3), arising from longer methylene sequences. Both sample $\mathbf{9}$ and $\mathbf{1 0}$ are semicrystalline by WAXS as confirmed by the presence of a diffraction peak at $2 \theta \approx 21^{\circ}$ corresponding to the (110) reflection of the orthorhombic form and/or (100) reflection of the pseudo-hexagonal form of PE (Figure S7A). In particular, sample $\mathbf{1 0}$ exhibits the higher degree of crystallinity (10\%). Likewise, SAXS data reported in Figure S7B confirm the presence of a broad correlation peak for crystalline samples generated by the broad distribution of defective crystals. It is worth of note that the presence of higher melting peak in sample obtained at longer reaction time provides indirect evidence for long crystallizable methylene segments, while the solubility in hexane implies that these sequences are chemically attached to those amourphous. 
Typical stress-strain curves of sample 7, 8 and $\mathbf{1 0}$ are shown in Figure 4, and the tensile properties are listed in Table 5. Sample 7 has a low modulus $(E=1.2 \mathrm{MPa})$, it is highly ductile with an elongation at break higher than $1500 \%$, and stress at break close to $0.2 \mathrm{MPa}$. Sample 7 behaves like a viscous liquid at higher elongation: it exhibits decreasing stress when the strain was substantially increased, suggesting stress-induced creeping of the macromolecular chains because the terpolymer network is not sufficiently cross-linked, i.e. the material is amorphous with a $T_{\mathrm{g}}$ of $-7{ }^{\circ} \mathrm{C}$. On the contrary, sample 8, semicrystalline $(4 \%)$ in the unstretched state, has a higher modulus $(E=3.9 \mathrm{MPa})$, a significant increased strength, an elongation at break of $1250 \%$, and it exhibits strain hardening at the late stage of deformation. Sample $\mathbf{8}$ had better elasticity than sample 7, as demonstrated by both the hysteresis experiments (Table 5, and Figure 4B/4C). The difference in tensile properties between sample $\mathbf{7}$ and $\mathbf{8}$ is the result of the change in crystallinity level, which strongly depends on the extent of composition drift. As a matter of fact, crystals in the unstretched sample $\mathbf{8}$ act as physical cross-link to transmit the mechanical tension and as nuclei to promote crystallization during stretching that usually starts from deformations very close the yielding point. $^{48}$
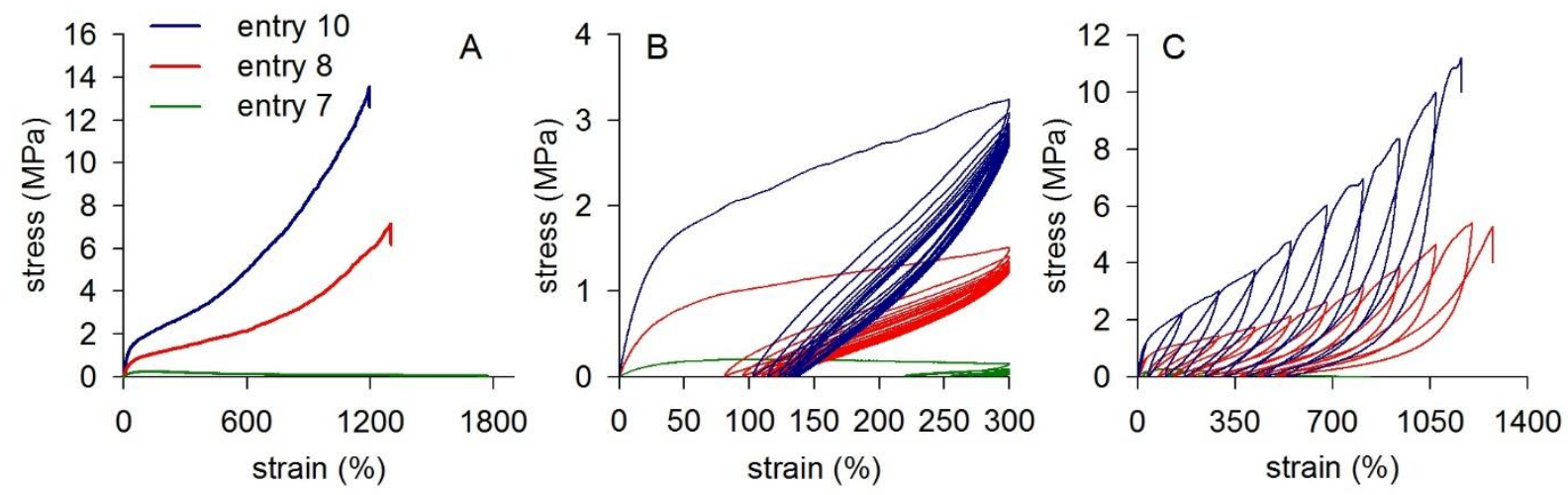

Figure 4. (A) Stress-strain curves, (B) stress-strain curves in the hysteresis experiments for a strain of 300\%, and (C) stress-strain curves during step cycle tensile deformation at different strain of sample 7, 8 and $\mathbf{1 0 .}$

Table 5. Mechanical properties of EPDMs obtained with 2a/ $\mathrm{Et}_{2} \mathrm{AlCl} / \mathrm{ETA}$.

\begin{tabular}{cccccccc}
\hline \multirow{2}{*}{ entry } & $\boldsymbol{E}^{a}$ & $\boldsymbol{\sigma}^{b}$ & $\boldsymbol{\varepsilon}^{c}$ & \multicolumn{2}{c}{ cyclic test 1 } & \multicolumn{2}{c}{ cyclic test 2 } \\
\cline { 5 - 9 } & $(\mathbf{M P a})$ & $(\mathbf{M P a})$ & $(\boldsymbol{\%})$ & $\mathbf{S R}_{\mathbf{I}}{ }^{d}$ & $\mathbf{S R}_{\mathbf{X}}{ }^{e}$ & $\mathbf{S R}_{\mathbf{4 2 0}}{ }^{f}$ & $\mathbf{S R}_{\mathbf{8 1 0} \%^{g}}$ \\
\hline 7 & $1.2 \pm 0.2$ & $0.2 \pm 0.02$ & $1587 \pm 267$ & 29 & 3 & 12 & $<1$
\end{tabular}


8

10

$6.8 \pm 0.5$

$14.7 \pm 1.2$

54

52

${ }^{a}$ Young's modulus; ${ }^{b}$ ultimate tensile strength; ${ }^{c}$ elongation at break; ${ }^{d}$ strain recovery measured after the first step in a step cycle test type at $300 \%$ strain; ${ }^{e}$ strain recovery measured after the last step in a step cycle test type at $300 \%$ strain; ${ }^{f}$ strain recovery measured after the strain at $420 \%$ in a step cycle test type at increasing strains; ${ }^{g}$ strain recovery measured after the strain at $810 \%$ in a step cycle test type at increasing strains.

Among the terpolymers from 2a, sample 10, obtained by using a lower amount of ENB in the feed, exhibits the highest modulus $(E=8.3 \mathrm{MPa})$, and remarkable strain hardening with ultimate tensile strength of $14.7 \mathrm{MPa}$. These data may be due to the highest crystallinity of sample $\mathbf{1 0}$ in the unstretched state, i.e., $10 \%$ (compared to $4 \%$ for entry $\mathbf{8}$ ). Besides, sample $\mathbf{1 0}$ exhibits more plastic deformation with lower strain recoveries than sample $\mathbf{8}$ (Table 5, and Figure 4B/4C).

Altogether, it can be inferred that a $[\mathrm{ENB}]_{0}$ as low as $0.035 \mathrm{~mol} \mathrm{~L}^{-1}$ causes steeper time drift in composition. This steep tapering profile leads to the fast formation of chains having longer ethylene crystallizable units. The presence of thicker crystals and higher amount of crystallinity $(10 \%)$ deteriorates the elastic behavior. On the contrary, for the highest $[\mathrm{ENB}]_{0}$ of $0.07 \mathrm{~mol} \mathrm{~L}^{-1}$ the composition drift profile occurs more gradually on the same time scale, and the resultant material has better elastomeric performance.

\section{The Case of Complex $2 \mathrm{~b}$}

The terpolymerization behavior of $\mathbf{2 b} / \mathrm{Et}_{2} \mathrm{AlCl} / \mathrm{ETA}$ was investigated for a reaction time between 1 and $4 \mathrm{~min}$ at $\mathrm{P} / \mathrm{E} / \mathrm{ENB}=4 / 1 / 0.5$, and at various $\mathrm{ENB}$ concentration in the feed between 0.035 and $0.14 \mathrm{~mol} \mathrm{~L}^{-1}$ for a time of $4 \mathrm{~min}$. Details of polymerization conditions and results are summarized in Table 6.

Table 6. Terpolymerization of ethylene with propylene and ENB by $\mathbf{2 b} / \mathrm{Et}_{2} \mathrm{AlCl} / \mathrm{ETA}{ }^{a}$

\begin{tabular}{|c|c|c|c|c|c|c|c|c|c|c|c|c|c|}
\hline \multirow{2}{*}{ entry } & \multirow{2}{*}{$\frac{[\mathrm{ENB}]_{0}}{\mathrm{~mol} / \mathrm{L}}$} & \multirow{2}{*}{$\mathbf{P} / \mathbf{E} / \mathbf{E N B}^{b}$} & \multirow{2}{*}{$\begin{array}{l}\text { time } \\
(\min )\end{array}$} & \multirow{2}{*}{$\frac{\text { yield }}{(\mathrm{mg})}$} & \multirow{2}{*}{ activity $^{c}$} & \multicolumn{3}{|c|}{$\begin{array}{c}\text { terpolymer } \\
\text { composition }(\mathrm{mol} \%)^{d}\end{array}$} & \multicolumn{2}{|c|}{$\begin{array}{c}(\text { co)monomer } \\
\text { conversion }(\%)^{e}\end{array}$} & \multirow{2}{*}{$\begin{array}{l}M_{\mathbf{w}}{ }^{f} \\
\times 10^{3}\end{array}$} & \multirow[t]{2}{*}{$\boldsymbol{M}_{\mathbf{w}} / \boldsymbol{M}_{\mathrm{n}}^{f}$} & \multirow{2}{*}{$\frac{T_{g}\left(T_{m}\right)^{g}}{\left({ }^{\circ} \mathrm{C}\right)}$} \\
\hline & & & & & & $\mathbf{E}$ & $\mathbf{P}$ & ENB & $\mathbf{P}$ & ENB & & & \\
\hline 11 & 0.07 & 4/1/0.5 & 1 & 287 & 3444 & 82.4 & 5.7 & 11.9 & 1.4 & 24.0 & 112 & 1.9 & 1 \\
\hline $3^{h}$ & 0.07 & 4/1/0.5 & 2 & 501 & 3006 & 80.3 & 6.5 & 13.2 & 2.8 & 44.9 & 101 & 1.9 & 5 \\
\hline 12 & 0.07 & 4/1/0.5 & 4 & 833 & 2499 & 84.8 & 4.5 & 10.7 & 3.4 & 64.4 & 102 & 2.2 & $-4(50)$ \\
\hline
\end{tabular}




$\begin{array}{rrrrrrrrrrrrrrrrr}\mathbf{1 3} & 0.035 & \mathbf{4 / 1 / 0 . 2 5} & 4 & 860 & 2580 & 89.8 & 4.2 & 6.0 & 3.7 & 84.0 & 93 & 2.0 & -6(77) \\ \mathbf{1 4} & 0.11 & \mathbf{4 / 1 / 0 . 7 5} & 4 & 897 & 2691 & 84.7 & 2.2 & 13.1 & 1.7 & 52.5 & 154 & 2.3 & 10 \\ \mathbf{1 5} & 0.14 & \mathbf{4 / 1 / 1} & 4 & 625 & 1875 & 81.9 & 2.6 & 15.5 & 1.3 & 31.0 & 132 & 2.2 & 19\end{array}$

${ }^{a}$ polymerization conditions: ethylene pressure, 1.01 bar; total volume, $50 \mathrm{~mL}($ toluene); $\mathrm{V} \mathrm{complex,} 2.5 \mu \mathrm{mol} ; \mathrm{Al} / \mathrm{V}=500 ; \mathrm{ETA} / \mathrm{V}=$ 10; temperature, $20{ }^{\circ} \mathrm{C} ;{ }^{b} \mathrm{P} / \mathrm{E} / \mathrm{ENB}$ feed ratio (mol/mol) in liquid phase; ${ }^{c}$ activity in $\mathrm{kg}_{\text {pol }} \times\left(\mathrm{mol}_{\mathrm{V}} \times \mathrm{h}\right)^{-1} ;{ }^{d}$ determined by $\mathrm{NMR} ;{ }^{e}$ the comonomer conversion was calculated by combining the NMR data, comonomer feed, and weight of the obtained terpolymer as reported in the supporting information; ${ }^{f}$ determined by SEC; ${ }^{g}$ determined by DSC (second heating); ${ }^{h}$ first reported in Table 1.

$\mathbf{2 b}$, having aromatic substituents on the imido ligand, has an initiation rate faster than its homologue 2a bearing the $t \mathrm{Bu}$ substituent on the imido fragment: an extremely rapid terpolymerization took place likely due to the electron-withdrawing nature of the imido ligand that increases the chance of the more electron-deficient $\mathbf{2} \mathbf{b}$ to be active, at least in the first stage of the reaction. As the reaction proceeds there was a significantly drop-off in activity, indicating a limited stability of $\mathbf{2 b}$. The presence of the electron-withdrawing imido ligand may account for inferior performance over time of $\mathbf{2} \mathbf{b}$, but it is likely that steric effects also play a role. Besides, $\mathbf{2} \mathbf{b}$ shows higher ENB affinity but lower affinity for propylene than its homolog 2a. This feature has previously been observed also with titanium complexes based on amidinate, ${ }^{24}$ and cyclic amidinato ligands with aliphatic substituents. ${ }^{51}$

When the polymerization was quenched after 1 min (entry 11), a terpolymer with a propylene content of $5.7 \mathrm{~mol} \%$ (equivalent to $1.4 \%$ conversion of added propylene) and ENB content of $11.9 \mathrm{~mol} \%$ (equivalent to $24.0 \%$ conversion of added ENB) was obtained. When the polymerization was quenched after $2 \min$ (entry $\mathbf{3}$ ), the conversion of both the comonomers doubles (equivalent to (co)monomer incorporations of $\mathrm{P}=6.5 \mathrm{~mol} \%$, and $\mathrm{ENB}=13.2 \mathrm{~mol} \%$ ) and the ethylene content decreases slightly. Samples $\mathbf{1 1}$ and $\mathbf{3}$ show only a glass transition event with $T_{\mathrm{g}}$ at 1 and $5{ }^{\circ} \mathrm{C}$, respectively, without any detectable $T_{\mathrm{m}}$. When the polymerization was quenched after 4 min (entry 12), the conversion of both the comonomers increases much less than in the first two minutes in favor of an increasing insertion rate of ethylene due to a significant composition drift. Consistent with the formation of longer ethylene sequences with the reaction proceeding and broad 
$\mathrm{CCD}$ due to the time drift, sample 12 exhibits also a broad melting event $\left(T_{\mathrm{m}}\right.$ at $\left.50{ }^{\circ} \mathrm{C}\right)$. Accordingly, the dominant feature of the stress-strain curve of sample $\mathbf{1 2}$ is the development of strain hardening (Figure 5A), which was disclosed by strain-induced crystallization. On the contrary, sample 3 exhibits decreasing stress when the strain was substantially increased, indicating stress-induced creeping of the polymer chains (Figure 5A).
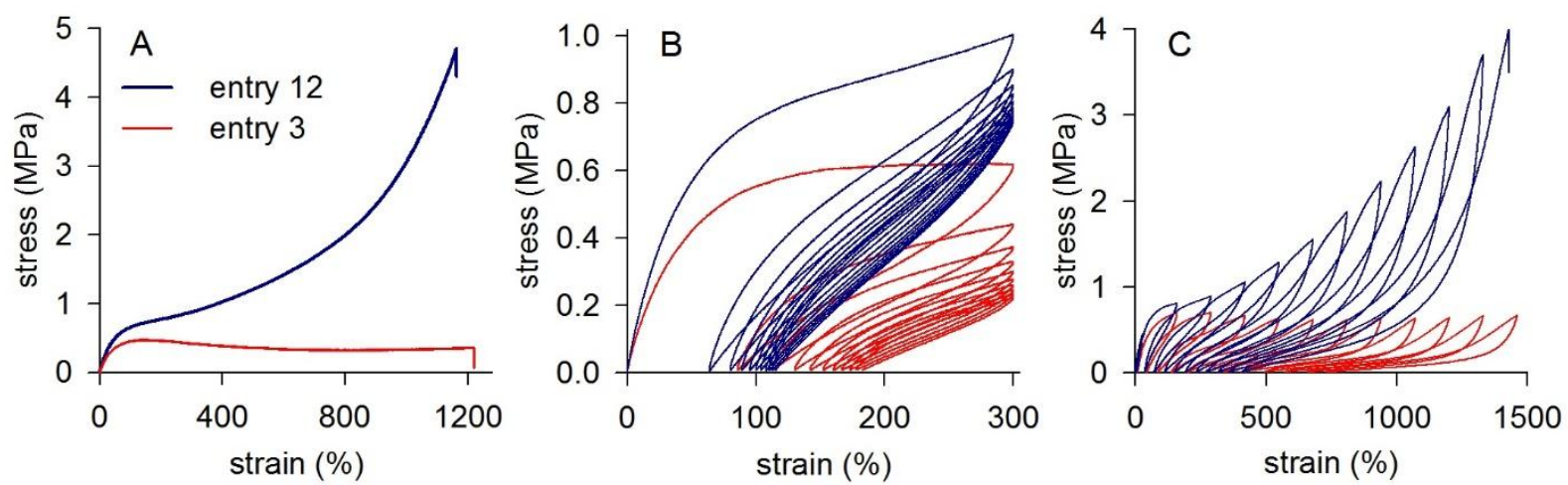

Figure 5. (A) Stress-strain curves, (B) stress-strain curves in the hysteresis experiments for a strain of 300\%, and (C) stress-strain curves during step cycle tensile deformation at different strain of sample $\mathbf{3}$ and $\mathbf{1 2 .}$

Table 7. Mechanical properties of selected EPDMs obtained with $2 \mathbf{b} / \mathrm{Et}_{2} \mathrm{AlCl} / \mathrm{ETA}$.

\begin{tabular}{|c|c|c|c|c|c|c|c|}
\hline \multirow{2}{*}{ entry } & \multirow{2}{*}{$\begin{array}{c}E^{a} \\
(\mathbf{M P a})\end{array}$} & \multirow{2}{*}{$\begin{array}{c}\sigma^{b} \\
(\mathbf{M P a})\end{array}$} & \multirow{2}{*}{$\begin{array}{c}\varepsilon^{c} \\
(\%)\end{array}$} & \multicolumn{2}{|c|}{ cyclic test 1} & \multicolumn{2}{|c|}{ cyclic test 2} \\
\hline & & & & $\mathbf{S R}_{\mathrm{I}}^{d}$ & $\mathbf{S R}_{\mathbf{X}}{ }^{e}$ & $\mathbf{S R}_{420 \%}{ }^{f}$ & $\mathbf{S R}_{810 \%}{ }^{g}$ \\
\hline 3 & $1.8 \pm 0.04$ & $0.47 \pm 0.01$ & $1190 \pm 154$ & 71 & 39 & 66 & 58 \\
\hline 12 & $2.2 \pm 0.1$ & $4.8 \pm 0.1$ & $1124 \pm 54$ & 79 & 62 & 73 & 71 \\
\hline 13 & $13.5 \pm 0.7$ & $14.0 \pm 3.5$ & $888 \pm 82$ & 66 & 54 & 64 & 51 \\
\hline 14 & $2.5 \pm 0.1$ & $12.0 \pm 2.8$ & $657 \pm 31$ & 88 & 72 & 87 & break $^{h}$ \\
\hline 15 & $95 \pm 20$ & $20.5 \pm 1.5$ & $444 \pm 27$ & 68 & 67 & 62 & break $^{h}$ \\
\hline
\end{tabular}

${ }^{a}$ Young's modulus; ${ }^{b}$ ultimate tensile strength; ${ }^{c}$ elongation at break; ${ }^{d}$ strain recovery measured after the first step in a step cycle test type at $300 \%$ strain; ${ }^{e}$ strain recovery measured after the last step in a step cycle test type at $300 \%$ strain; ${ }^{f}$ strain recovery measured after the strain at $420 \%$ in a step cycle test type at increasing strains; ${ }^{g}$ strain recovery measured after the strain at $810 \%$ in a step cycle test type at increasing strains; ${ }^{h}$ the specimens break before the strain at $810 \%$ in a step cycle test type at increasing strains.

Figure 5B and 5C show the stress-strain curves during cyclic tensile deformation at $300 \%$ strain, and with increasing the applied strain, respectively. The strain recovery of sample $\mathbf{3}$ goes from 71 to $39 \%$ as the load cycle time increased and from 66 to $58 \%$ under the applied strain of 
$420 \%$ and $810 \%$, respectively (Table 7). In comparison, sample 12 gave best elastomeric performance. Increasing the applied strain, the recovery of sample 12 was almost stable over 70\%, and goes from 79 to $62 \%$ as the load cycle time increased.

Increasing the concentration of ENB in the feed from 0.035 to $0.11 \mathrm{~mol} \mathrm{~L}^{-1}$ did not result in any substantial change in the activity (and terpolymer yield). However, a further increase in the concentration of ENB in the feed resulted in a loss in activity likely due to a favored ENB coordination/insertion, which competes with the homopolymerization of ethylene and propylene insertion, and contributes to slow down the rate of terpolymerization. Increasing the charged ENB, its content in the terpolymer increased linearly, and easily reached $15.5 \mathrm{~mol} \%$ for $[\mathrm{ENB}]_{0}=0.14$ mol L ${ }^{-1}$ (equivalent to $31.0 \%$ conversion of added ENB) (Figure 6). Although most of the EPDMs produced at various ENB feedstock concentration are in a comparable range, a significant increase in the molecular weight was observed increasing the ENB concentration from 0.035 to $0.11 \mathrm{~mol} \mathrm{~L}^{-1}$. In analogy to the results previously reported by some us ${ }^{36}$ it seems that the coordination of ENB slows down chain termination reactions to some extent, at least more than propylene does. Regarding the $M_{\mathrm{w}} / M_{\mathrm{n}} \mathrm{s}$, all were found in the range 2.0-2.3, consistent with single homogeneous catalytic species and good selectivity in the terpolymerization.

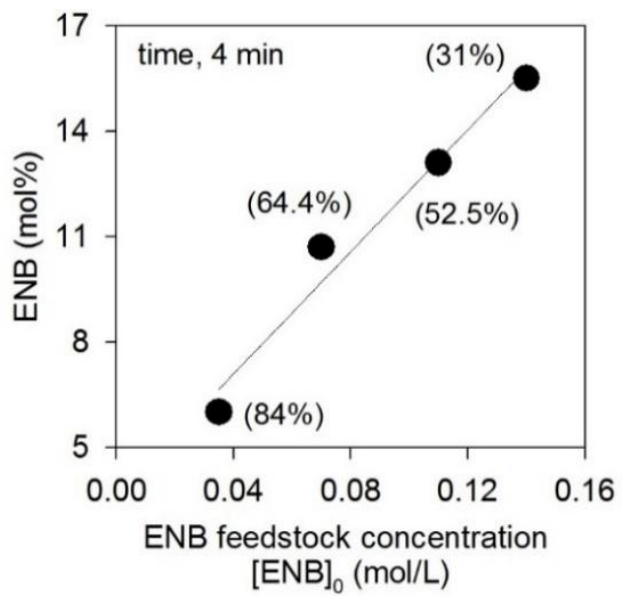

Figure 6. Plot of ENB incorporated in the terpolymer $v s$ concentration of ENB in the feed. ENB conversion is shown in parentheses. 
DSC heating curves of non-isothermal crystallized terpolymers produced by $\mathbf{2} \mathbf{b}$ varying the concentration of ENB in the feed are reported in Figure 7. Generally, the diene content has a large effect on $T_{\mathrm{g}}$, which ranges from -6 to $19{ }^{\circ} \mathrm{C}$ with the increasing of ENB from 6.0 to $15.5 \mathrm{~mol} \%$. This is somehow an expected finding, since ENB is bulkier than ethylene and propylene, and slows down the rotational movement of the polymer chains. Besides, while samples $\mathbf{1 4}$ and $\mathbf{1 5}$ obtained at $[\mathrm{ENB}]_{0}>0.1 \mathrm{~mol} \mathrm{~L}{ }^{-1}$ exhibit only a $T_{\mathrm{g}}$, samples $\mathbf{1 3}$ and $\mathbf{1 2}$ obtained at $[\mathrm{ENB}]_{0}=0.035$ and $0.07 \mathrm{~mol}$ $\mathrm{L}^{-1}$, respectively, also show a broad endothermic event. Particularly for sample 13, the melting event begins at low temperature, extends over $80{ }^{\circ} \mathrm{C}$ temperature range with the peak maximum at about $78{ }^{\circ} \mathrm{C}$. The multimodal shape of the endothermic event may indicate that crystallizable segments with different levels of methylene sequences exist, namely chain segments with high propylene and ENB content, formed at the beginning of the polymerization, melting at low temperature, and blocks with low comonomers content, formed at the end, melting at higher temperature. Consistent with DSC data, sample 13 crystallizes in the orthorhombic form of PE, as evident by the $(110)$ and $(200)$ reflections at $2 \theta \approx 21$ and $24^{\circ}$, respectively (inset of Figure 7 ) with a moderate degree of crystallinity (13\%). In addition, SAXS profile shows a broad correlation peak, centered at $q \approx 0.55 \mathrm{~nm}^{-1}$, indicating a large thicknesses distribution of crystalline and amorphous layers (Figure S8B).

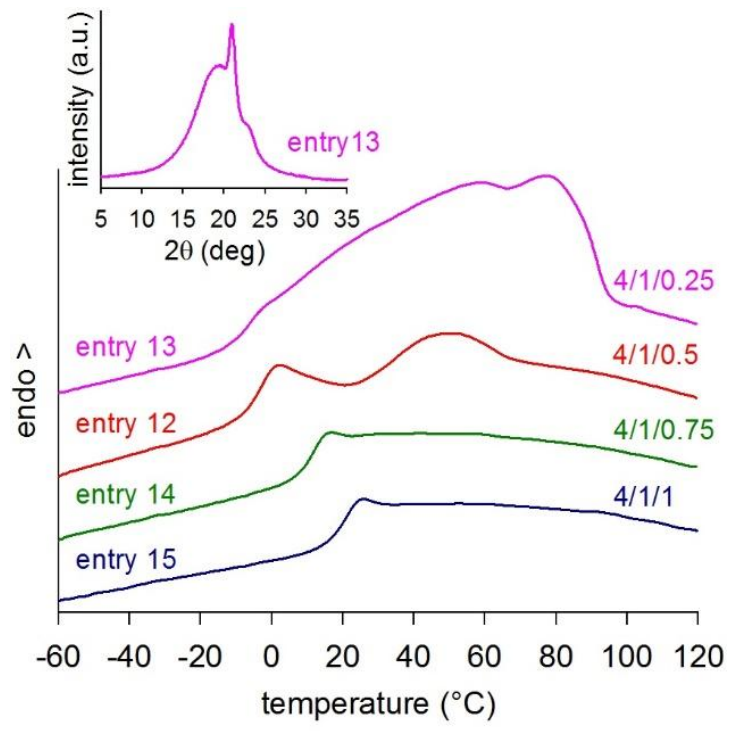


Figure 7. $\mathrm{DSC}$ heating scan of $\mathrm{E} / \mathrm{P} / \mathrm{ENB}$ terpolymers obtained by $\mathbf{2} \mathbf{b} / \mathrm{Et}_{2} \mathrm{AlCl} / \mathrm{ETA}$ by varying the concentration of ENB in the feed. At the top left the WAXS pattern of compression-molded sample 13.

Figure 8A shows representative stress-strain curves for entries 12-15. Tensile data are listed in Table 7. Overall, these samples show a very different behavior, both at small (inset of Figure 8A) and large strain. They exhibit properties from thermoplastic to elastomer, which, however, may originate from the concomitant effects of composition, CCD, which in turn strongly affect also the $T_{\mathrm{g}}$, and molecular weight.

Sample 15, amorphous in the unstretched state (Figure S8A), displays the behavior of a tough thermoplastic with relatively high modulus $(E=95 \mathrm{MPa})$, high tensile strength $(\sigma=20.5$ $\mathrm{MPa})$, and low strain at break $(\sim 400 \%)$. It is inferred that the tensile properties of sample 15 are strongly affected by the high content of ENB (15.5 mol\%), and its high $T_{\mathrm{g}}\left(19{ }^{\circ} \mathrm{C}\right)$. By decreasing the content of ENB and, at the same time, increasing the content of ethylene, the resultant terpolymers have lower modulus and lower tensile strength, associated to an improved elongation at break (entries 14 and 12, Table 7). Sample 12 exhibits typical elastomeric behavior. It is highly ductile with a strain to break of about $1100 \%$. Sample $\mathbf{1 4}$ has a behavior similar to sample $\mathbf{1 2}$ at low strain (inset of Figure 8A) but a more remarkable strain hardening at large deformation. Such difference in the onset and extent of strain hardening can be likely due to the higher molecular weight of sample $14 .^{52}$ By contrast, sample 13 exhibits considerable plastomeric behavior. This may originate from the fact that sample $\mathbf{1 3}$ is already crystalline in the unstretched state, as a result of steeper composition drift, and hence broader CCD, that occurs when the polymerization is carried out at low concentration of ENB in the feed. 

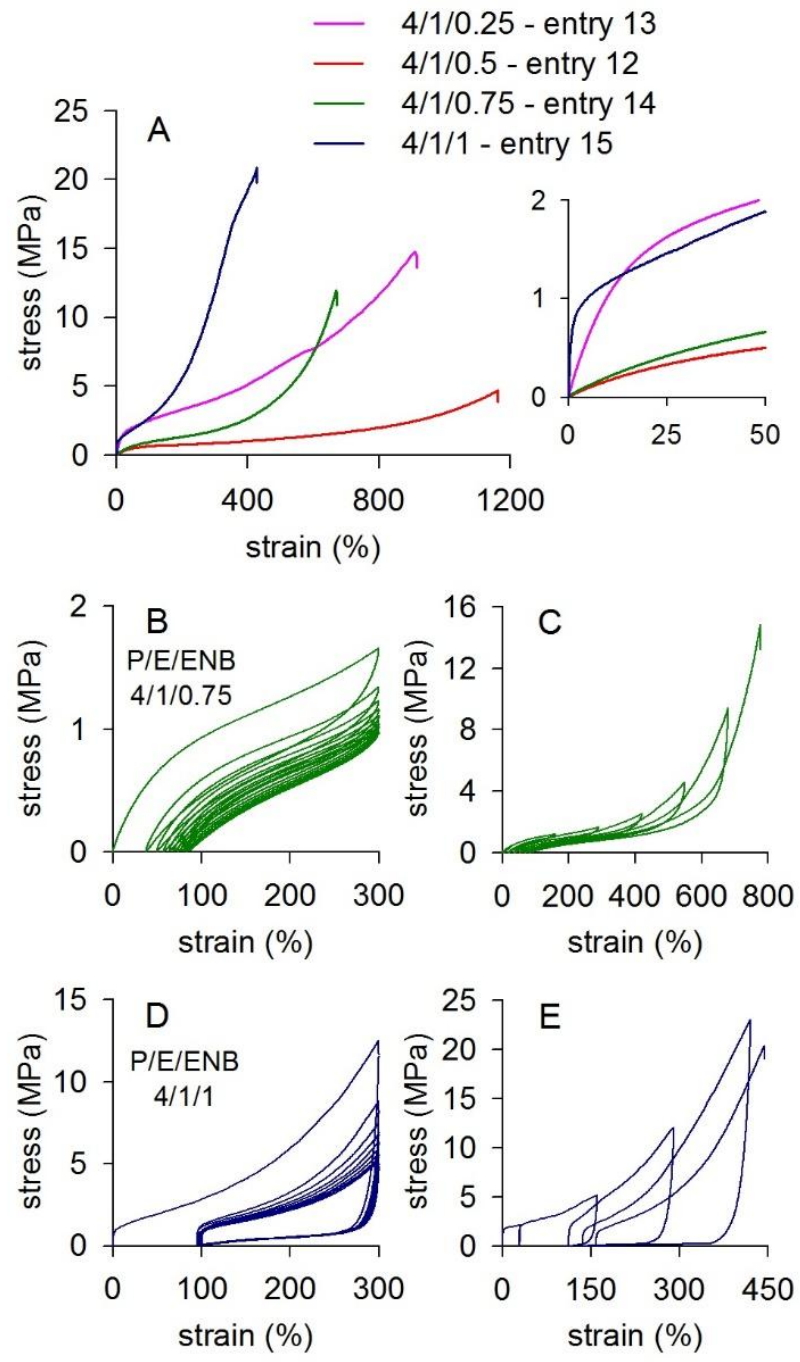

Figure 8. (A) Stress-strain curves of sample 12-15, (B) stress-strain curves of sample 14 in the hysteresis experiments for a strain of 300\%, (C) stress-strain curves of sample $\mathbf{1 4}$ during step cycle tensile deformation at different strain, (D) stress-strain curves of sample $\mathbf{1 5}$ in the hysteresis experiments for a strain of $300 \%$, (E) stress-strain curves of sample 15 during step cycle tensile deformation at different strain.

As a final consideration, the obtained terpolymers were subjected to hysteresis experiments. The first one was performed under the fixed strain of $300 \%$ over 10 cycles (Figure 8B and 8D). All the polymers suffer permanent deformation after the 1st cycle, and exhibit characteristic behavior associated with stress softening phenomenon for which the stress during retraction is lower than that during stretching at the same strain. ${ }^{53}$ This softening effect is remarkable for sample 15. A higher content of ENB, and hence the presence of glassy domains, making the movement of the polymer chain slower, may account for the severe decline of stress during retraction in the case of sample $\mathbf{1 5}$ 
(Figure 8D). However, it is worth of note that the strain recovery of sample $\mathbf{1 5}$ was almost stable (68-67\%) over the whole cycle tensile test, while the other samples displayed a decreasing trend with the load cycle time (Table 7 and Figure 9A).
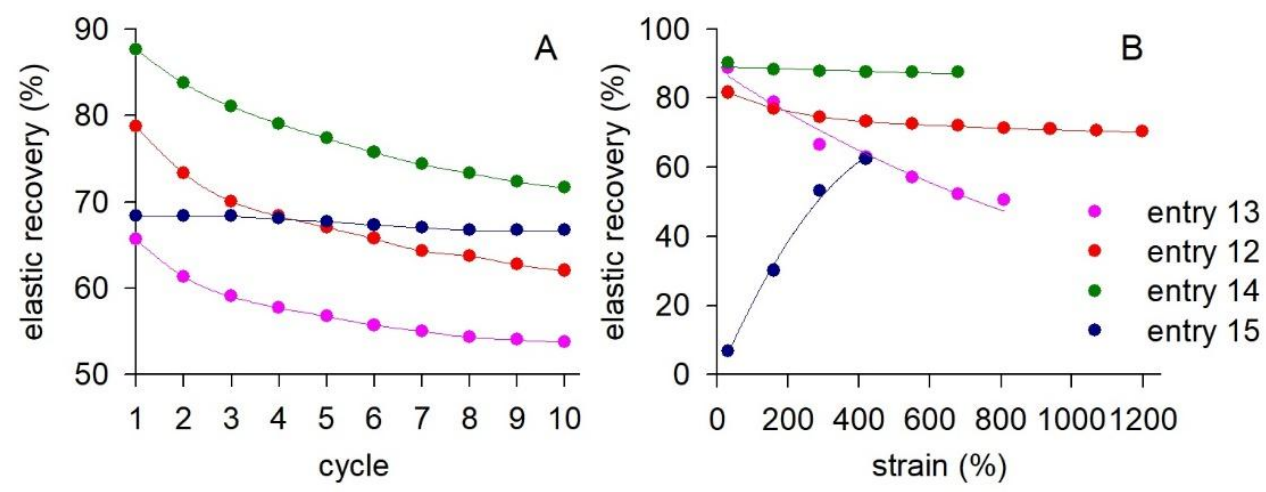

Figure 9. (A) strain recovery as a function of cycle number at $300 \%$ of strain; (B) strain recovery as a function of the applied strain.

In the second set of cyclic experiments, the samples were extended step by step up to different strains. As typical example, the stress-strain curve during cyclic tensile deformation of sample 14 and 15 is shown in Figure 8C and 8E, respectively, while the elastic recovery data are plotted as a function of the applied strain in Figure 9B. For sample 14 and 12, the strain recovery decreased rapidly at lower applied strain and then leveled off at higher applied strain; in particular, the SR value for sample 14 was almost stable at about $87 \%$ for strain spanning from 160 to $680 \%$. On the contrary, for sample $\mathbf{1 3}$ the recovery decreased nearly linearly as the applied strain increased over the entire cyclic test. Generally, the worst performance of sample $\mathbf{1 3}$ in term of elasticity could be attributed to its widest $\mathrm{CCD}$, which results from a more pronounced composition drift, and higher crystallinity among the series. By contrast, for sample $\mathbf{1 4}$ it is demonstrated that a minor, but still significant, composition drift is beneficial to impart excellent elasticity to the material. Moreover, the presence of glassy blocks may also account for.

The dependence of strain recovery on the applied deformation was significantly different for sample 15. Specifically, the SR values increases up to $62 \%$ with increasing the applied strain to $420 \%$. It may help to recall that sample $\mathbf{1 5}$ has a $T_{\mathrm{g}}$ very close to room temperature and, in this 
particular case, tensile properties are strongly affected by the temperature at which the experiments were performed. Moreover, different strain recovery mechanisms are involved when materials are tested in a glassy phase across or just below its $T_{\mathrm{g}} .{ }^{54}$ Ongoing studies aim to clarify the role of chain architecture/composition and of ENB content on the elastomeric performance of these materials.

\section{$\underline{\text { Remelting Processability for Recycle Use }}$}

The reprocessability of the obtained EPDMs was tested by repeated melting and molding the broken films using the same experimental conditions of their original preparation (i.e., in a press at $90{ }^{\circ} \mathrm{C}$ and 50 bar for $5 \mathrm{~min}$, then cooled to room temperature thus obtaining recycled films with a thickness of about $150 \mu \mathrm{m}$ ) and evaluating their mechanical properties. As an example, the stress-strain curve of pristine sample $\mathbf{5}$ and recycled films is compared in Figure 10A. It can be seen that even after the third processing cycle, mechanical properties changes marginally. Notably, after being recycled, sample 5 still exhibited excellent elasticity with recoveries comparable to those of pristine sample (Figure 10B/C).
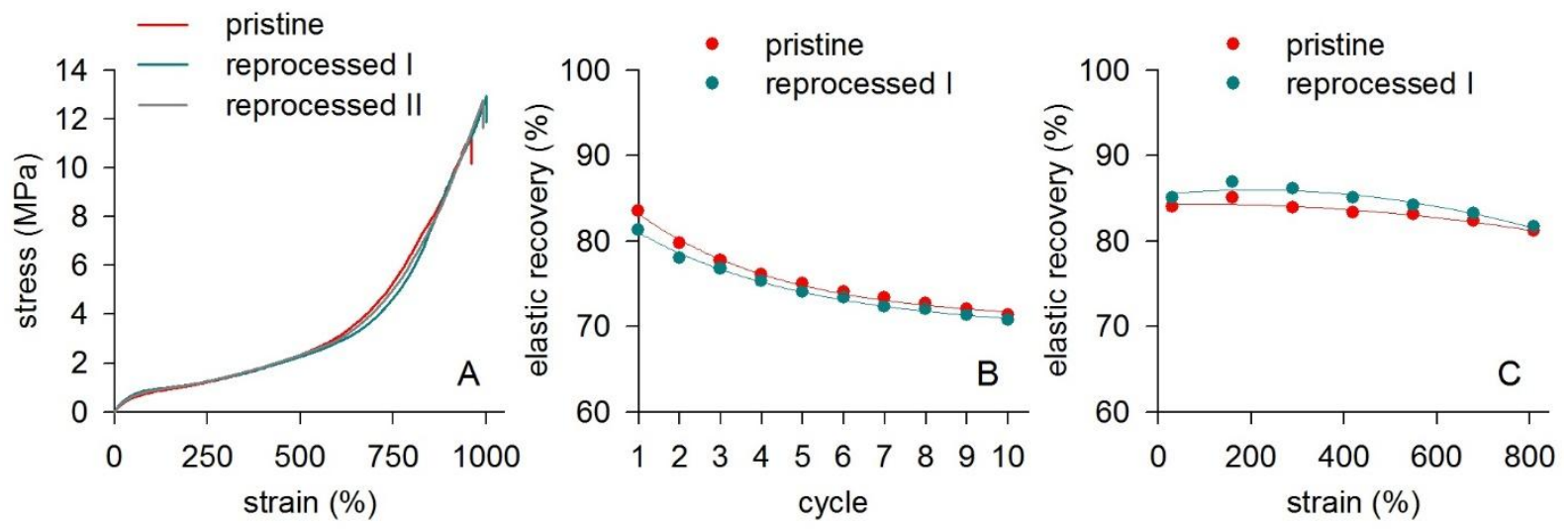

Figure 10. (A) Stress-strain curves of sample 5 (Table 2 and 3) during monotonic tensile deformation; (B) strain recovery as a function of cycle number at $300 \%$ of strain; (C) strain recovery as a function of the applied strain: comparison between pristine and reprocessed samples.

\section{$\underline{\text { Morphology by AFM }}$}

AFM height contrast images of selected terpolymers (i.e., entries $\mathbf{8 , 1 0}$ and $\mathbf{1 3}$ ) are reported in Figure 11. The morphological characterization was performed only on samples presenting, at least, a moderate degree of crystallinity to fully resolve the morphology and to avoid artifacts 
related with the AFM tip radius and the small crystal size. Moreover, it is worth pointing out that samples for AFM characterization followed a crystallization protocol different from that used to prepare compression molded films for mechanical and structural characterization. In these crystallization conditions, where the sample is cooled down from the melt to $-50{ }^{\circ} \mathrm{C}$ at $2.5^{\circ} \mathrm{C} \mathrm{min}^{-1}$, crystallization is enhanced, and for these samples, morphology can be easily detected with AFM measurements. AFM images of samples $\mathbf{8}$ and $\mathbf{1 0}$ reported in Figure 11A and B, respectively, mainly show the presence of bundle-like morphology, however the presence of fringed micellar crystals cannot be excluded. A fraction of granular texture is observed in sample $\mathbf{8}$ while larger superstructures (average size 100-200 nm) are visible in sample $\mathbf{1 0}$ according with higher degree of crystallinity of this sample. Sample $\mathbf{1 3}$ shows a well-organized morphology (Figure 11C) characterized by bundle-like structure and small spherulites resembling starfish-like morphology. AFM images collected at smaller scan-size $(0.2 \times 0.2 \mu \mathrm{m}$, Figure S9) highlight lamellar details with estimated crystalline thickness of about $2 \mathrm{~nm}$ in sample $\mathbf{1 0}$ and $\mathbf{1 3 .}$

It is well known that morphology has a central role in the elastomeric performances of semicrystalline materials, and it is the result of composition, chain architecture, thermal history, phase separation etc. Morphological characterization of similar EPDMs, to best of our knowledge, has not been systematically assessed in literature. A comparison with the morphologies reported for random copolymers of ethylene with 1-octene shows that structures similar to those of samples $\mathbf{8}$ and $\mathbf{1 0}$ with bundled crystals and very small spherulites are present in samples with 1-octene content higher than $7 \mathrm{~mol} \%$ (melting range $0-70{ }^{\circ} \mathrm{C}$ and crystallinity of about $10 \%$ ), and moreover, these samples show good elastomeric behavior with large strain recovery and they do not exhibit yield maximum. ${ }^{55-57}$ Samples of copolymers presenting slightly lower 1-octene content have thicker lamellae, well defined spherulites and increased crystallinity that reduces the elastomeric characteristics; a behavior like that observed in sample 13. However, if the trend crystallinity/morphology vs elastomeric behavior is maintained, compared to systems reported in literature with similar melting temperatures, our EPDMs seem to crystallize in well-defined 
structures as a consequence of composition drift that produces chain segments with more consecutive ethylene units.
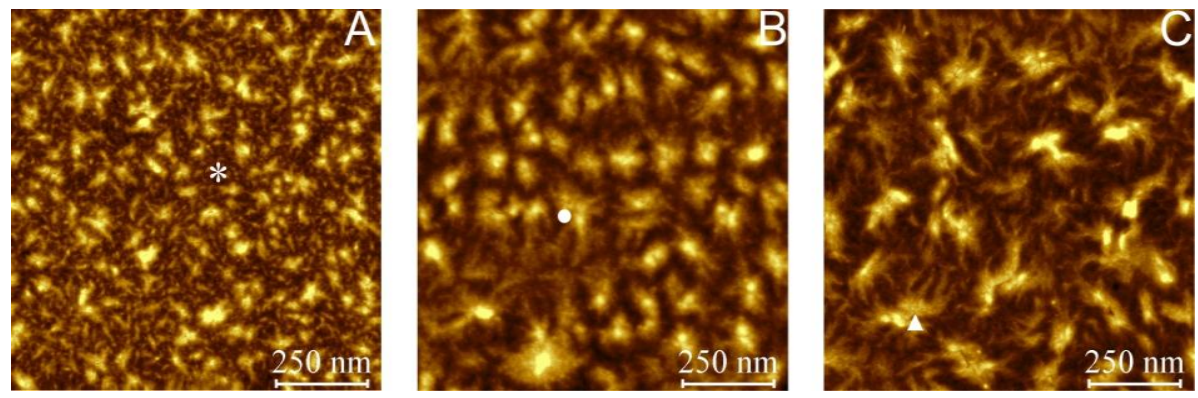

Figure 11. AFM height images showing $1 \mu \mathrm{m} \times 1 \mu \mathrm{m}$ scans of sample $\mathbf{8}(\mathrm{A}), \mathbf{1 0}(\mathrm{B})$, and $\mathbf{1 3}(\mathrm{C})(*$ granular texture; bundle-like structures; $\boldsymbol{\Delta}$ small spherulites resembling starfish-like morphology).

\section{Ethylene/a-olefin/ENB Terpolymers}

It is interesting to replace propylene with higher $\alpha$-olefins, such as 1-hexene (HEX) and 1octene (OCT) because longer $\alpha$-olefins are the best choice to prevent crystallization of ethylene segments, and thereby to obtain low $-T_{\mathrm{g}}$ materials. Preliminary experiments on terpolymerization of ethylene with HEX (or OCT) and ENB was carried out by using $\mathbf{2 a} / \mathrm{Et}_{2} \mathrm{AlCl} / \mathrm{ETA}$. The results are summarized in Table 8.

Terpolymerizations in the presence of HEX and OCT proceed with lower activities than those in the presence of propylene, and the molecular weight of the obtained terpolymers are significantly lower likely due to an increased rate of $\beta-\mathrm{H}$ elimination and subsequent chain-transfer from the last inserted HEX or OCT unit. The terpolymers show high thermal stability (Figure S10A), a glass transition event at low temperature (about $-24^{\circ} \mathrm{C}$ ), and a broad melting endotherm with $T_{\mathrm{m}}$ from 45 to $50{ }^{\circ} \mathrm{C}$ (Figure $\mathrm{S} 10 \mathrm{~B}$ ). The low $-M_{\mathrm{w}}$ is a serious limitation with respect to the goal of determining their tensile properties. Ongoing studies are underway to adjust the molecular weight.

Table 8. Terpolymerization of ethylene with longer $\alpha$-olefins and ENB by $\mathbf{2 a} / \mathrm{Et}_{2} \mathrm{AlCl} / \mathrm{ETA}{ }^{a}$

\begin{tabular}{|c|c|c|c|c|c|c|c|c|c|c|c|c|}
\hline \multirow{2}{*}{ entry } & \multirow{2}{*}{$\begin{array}{l}\text { comonomer } \\
(\mathbf{Y}, \text { type })^{b}\end{array}$} & \multirow{2}{*}{$\begin{array}{r}\text { time } \\
(\min )\end{array}$} & \multirow{2}{*}{$\frac{\text { yield }}{(\mathrm{mg})}$} & \multirow[t]{2}{*}{ activity $^{c}$} & \multicolumn{3}{|c|}{$\begin{array}{c}\text { terpolymer } \\
\text { composition }(\mathbf{m o l} \%)^{d} \\
\end{array}$} & \multicolumn{2}{|c|}{$\begin{array}{c}\begin{array}{c}(\text { co)monomer } \\
\text { conversion }(\%)^{e}\end{array} \\
\end{array}$} & \multirow{2}{*}{$\begin{array}{r}M_{\mathbf{w}}{ }^{f} \\
\times \times 0^{3}\end{array}$} & \multirow{2}{*}{$\boldsymbol{M}_{\mathrm{w}} / \boldsymbol{M}_{\mathbf{n}}^{f}$} & \multirow{2}{*}{$\begin{array}{c}\boldsymbol{T}_{\boldsymbol{g}}\left(\boldsymbol{T}_{\boldsymbol{m}}\right)^{g} \\
\left({ }^{\circ} \mathbf{C}\right)\end{array}$} \\
\hline & & & & & $\mathbf{E}$ & $\mathbf{Y}$ & ENB & $\mathbf{Y}$ & ENB & & & \\
\hline
\end{tabular}




$\begin{array}{rrrrrrrrrrrrrrr}16 & \text { HEX } & 6 & 375 & 750 & 84.1 & 7.3 & 8.6 & 4.0 & 48.0 & 43 & 2.1 & -24(45) \\ 17 & \text { OCT } & 4 & 237 & 711 & 87.2 & 4.4 & 8.3 & 1.0 & 14.0 & 48 & 2.1 & -23(47) \\ 18 & \text { OCT } & 8 & 515 & 773 & 83.1 & 8.6 & 8.3 & 3.8 & 28.1 & 50 & 2.1 & -24(50)\end{array}$

${ }^{a}$ polymerization conditions: ethylene pressure, 1.01 bar; total volume, $50 \mathrm{~mL}$ (toluene); $\mathrm{V}$ complex, $2.5 \mu \mathrm{mol} ; \mathrm{Al} / \mathrm{V}=500 ; \mathrm{ETA} / \mathrm{V}=$ 10; temperature, $20{ }^{\circ} \mathrm{C} ;{ }^{b} \mathrm{P} / \mathrm{Y} / \mathrm{ENB}$ feed ratio (mol/mol) in liquid phase, $4 / 1 / 0.5 ;{ }^{c}$ activity in $\mathrm{kg}_{\mathrm{pol}} \times\left(\mathrm{mol}_{\mathrm{V}} \times \mathrm{h}\right)^{-1} ;{ }^{d}$ determined by $\mathrm{NMR}$; ${ }^{e}$ the comonomer conversion was calculated by combining the NMR data, comonomer feed, and weight of the obtained terpolymer as reported in the supporting information; ${ }^{f}$ determined by SEC; ${ }^{g}$ determined by DSC (second heating).

\section{CONCLUSIONS}

In summary, high-ethylene heterogeneous EDPMs are synthesized through the semi-batch terpolymerization of ethylene with propylene and ENB catalyzed by some imido V(IV) complexes, differing in the (co)ligand substituents, in combination with $\mathrm{Et}_{2} \mathrm{AlCl}$ and ETA. Terpolymers are heterogeneous because significant time drift in composition occurs due the feed policy, the high initiation rate and fast comonomer consumption. This drift causes variation in the instantaneous feed comonomer ratio, and hence in the chemical composition of the terpolymer over the period of conversion. The resultant EDPMs are composed of chains rich in propylene and ENB initially formed when their concentration is at maximum, and ethylene-rich chains formed subsequently, when low comonomer amount left in the reaction mixture. Beyond the uncertainty of comonomer(s) positioning, the terpolymers exhibit interesting tensile properties at room temperature as solid films, from soft thermoplastic to elastomer. The properties are dictated by the extent of composition drift, which in turn strongly depends on the polymerization conditions and ligand set. In proper experimental conditions, EDPMs behave as TPEs without the need of vulcanization, polymer blending and reinforcement through the addition of fillers. They exhibit high elasticity, strain hardening at large deformation, excellent shape retention properties, and remelting processability with no fall in properties even after three cycles. Examination of tensile behavior demonstrate the needful presence of ethylene sequences, long enough to crystallize during deformation, and to act as physical knots in the elastomeric network, to ensure high elasticity and desired recovery. 
While the high $T_{\mathrm{g}} \mathrm{s}$ are a limitation for application in cold weather climates, the heterogeneous EPDMs reported in this study have a number of advantages and may have application as compatibilizers. The broad CCD and chain-to-chain composition drift enable the materials to be easily (re)processed without sacrificing their elasticity. In addition, the high-ENB content may favor fast cure, good heat aging characteristics, higher cross-link densities, and blending with SBR.

\section{ACKNOWLEDGEMENTS}

We are grateful to Fulvia Greco for the acquisition of NMR spectra, and Daniele Piovani for SEC measurements.

\section{ASSOCIATED CONTENT}

The Supporting Information is available free of charge on the ACS Publications website at DOI Additional characterization of terpolymers.

\section{NOTES AND REFERENCES}

1. Wang, W.; Lu, W.; Goodwin, A.; Wang, H.; Yin, P.; Kang, N.-G.; Hong, K.; Mays, J.W. Recent advances in thermoplastic elastomers from living polymerizations: Macromolecular architectures and supramolecular chemistry. Prog. Polym. Sci. 2019, 95, 1-31.

2. Vidal, F.; Watson, E.M.; Chen, E.Y.-X. All-Methacrylic Stereoregular Triblock Co-polymer Thermoplastic Elastomers Toughened by Supramolecular Stereocomplexation. Macromolecules 2019, 52, 7313-7323.

3. Machat, M.R.; Lanzinger, D.; Drees, M.; Altimann, P.J.; Herdtweck, E.; Rieger, B. HighMelting, Elastic Polypropylene: A One-Pot, One-Catalyst Strategy toward Propylene-Based Thermoplastic Elastomers. Macromolecules 2018, 51, 914-929.

4. Pierro, I.; Zanchin, G.; Parisini, E.; Martí-Rujas, J.; Canetti, M.; Ricci, G.; Bertini, F.; Leone, G. Chain-Walking Polymerization of $\alpha^{-}$Olefins by $\alpha^{-}$Diimine Ni(II) Complexes: Effect of Reducing the Steric Hindrance of Ortho- and Para-Aryl Substituents on the Catalytic Behavior, Monomer Enchainment, and Polymer Properties. Macromolecules 2018, 51, 801-814. 
5. Matyjaszewski, K.; Tsarevsky N.V. Macromolecular engineering by atom transfer radical polymerization. J. Am. Chem. Soc. 2014, 136, 6513-6533.

6. Aoshima, S.; Kanaoka, S. A renaissance in living cationic polymerization. Chem. Rev. 2009, $109,5245-5287$.

7. Hotta, A.; Cochran, E.; Ruokolainen, J.; Khanna, V.; Fredrickson, G. H.; Kramer, E. J.; Shin, Y. W.; Shimizu, F.; Cherian, A. E.; Hustad, P. D.; Rose, J. M.; Coates, G. W. Semicrystalline thermoplastic elastomeric polyolefins: Advances through catalyst development and macromolecular design Proc. Natl. Acad. Sci. U. S. A. 2006, 103, 15327-15332.

8. Hawker, C.J.; Bosman, A.W.; Harth, E. New polymer synthesis by nitroxide mediated living radical polymerizations. Chem. Rev. 2001, 101, 3661-3688.

9. Dai, S.; Li, S.; Xu, G.; Chen, C. Direct Synthesis of Polar Functionalized Polyethylene Termoplastic Elastomer. Macromolecules 2020, 53, 2539-2546.

10. Gao, Y.; Liu, W., Zhu, S. Thermoplastic Polyolefin Elastomer Blends for Multiple and Reversible Shape Memory Polymers. Ind. Eng. Chem. Res. 2019, 58, 19495-19502.

11. Pierro, I.; Leone, G.; Zanchin, G.; Canetti, M.; Ricci, G.; Bertini, F. Polyolefin thermoplastic elastomers from 1-octene copolymerization with 1-decene and cyclopentene. Eur. Polym. J. 2017, 93, 200-211.

12. Wang, Y.; Hillmyer, M. A. Oxidatively Stable Polyolefin Thermoplastics and Elastomers for Biomedical Applications. ACS. Macro Lett. 2017, 6, 613-618.

13. O’Connor, K.S.; Watts, A.; Vaidya, T.; LaPointe, A.M.; Hillmyer, M.A.; Coates, G.W. Controlled Chain Walking for the Synthesis of Thermoplastic Polyolefin Elastomers: Synthesis, Structure, and Properties. Macromolecules 2016, 49, 6743-6751.

14. Leone, G.; Mauri, M.; Pierro, I.; Ricci, G.; Canetti, M.; Bertini, F. Polyolefin thermoplastic elastomers from 1-octene chain-walking polymerization. Polymer 2016, 100, 37-44. 
15. Moshonov, M.; Aharonovich, S.; Eisen, M.S. Tailor-Made Thermoplastic Elastomeric Stereoblock Polypropylenes by Modulation of Monomer Pressure. Macromolecules 2016, 49, 9287-9290.

16. Crawford, K. E.; Sita, L. R. De Novo Design of a New Class of "Hard-Soft" Amorphous, Microphase-Separated, Polyolefin Block Copolymer Thermoplastic Elastomers. ACS Macro Lett. $\mathbf{2 0 1 5}, 4,921-925$.

17. Leone, G.; Mauri, M.; Bertini, F.; Canetti, M.; Piovani, D.; Ricci, G. Ni(II) $\alpha^{-}$DiimineCatalyzed $\alpha$ - Olefins Polymerization: Thermoplastic Elastomers of Block Copolymers. Macromolecules 2015, 48, 1304-1312.

18. Deplace, F.; Scholz, A. K.; Fredrickson, G. H.; Kramer, E. J.; Shin, Y.-W.; Shimizu, F.; Zuo, F.; Rong, L.; Hsiao, B. S.; Coates, G. W. Tough and Elastic Thermoplastic Organogels and Elastomers Made of Semicrystalline Polyolefin-Based Block Copolymers. Macromolecules 2012, 45, $5604-5618$.

19. Kinsuk, N. Thermoplastic elastomers based on PP/EPDM blends by dynamic vulcanization. Rubber Chem. Technol. 2007, 80, 504-519.

20. Kresge, E.N. Polyolefin Thermoplastic Elastomer Blends. Rubber Chem. Technol. 1991, 64, 469-479.

21. Ishikawa, M.; Sugimoto, M.; Inoune, T. Mechanism of toughening for polypropylene blended with ethylene-propylene-diene rubber following selective crosslinking. J. Appl. Polym. Sci. 1996, $62,1495-1502$.

22. Yang, H.; Zhang, X.; Qu, C.; Li, B.; Zhang, L., Zhang, Q.; Fu, Q. Largely improved toughness of PP/EPDM blends by adding nano-SiO 2 particles. Polymer 2007, 48, 860-869.

23. Cheremisinoff, N.P. Spotlight on EPDM Elastomers. Polym. Plast. Technol. Eng. 1992, 31, 713-744.

24. van Doremale, G.; van Duin, M.M Valla, M.; Berthoud, A. On the Development of Titanium $\kappa^{1}$-Amidinate Complexes, Commercialized as Keltan ACE ${ }^{\mathrm{TM}}$ Technology, Enabling the Production 
of an Unprecedented Large Variety of EPDM Polymer Structures. J Polym. Sci. Pol. Chem. 2017, $55,2877-2891$.

25. Ravishankar, P.S. Treatise on EPDM. Rubber Chem. Technol. 2012, 85, 327-349.

26. Kresge, E. N. Science and serendipity in polyolefin elastomer development. Rubber Chem. Technol. 2010, 83, 227-234.

27. Zhang, G.; Zhou, X.; Liang, K.; Guo, B.; Li, X.; Wang, Z.; Zhang, L. Mechanically Robust and Recyclable EPDM Rubber Composites by a Green Cross-Linking Strategy. ACS Sustainable Chem. Eng. 2019, 7, 11712-11720.

28. Starzewski, A.O.; Steinhauser, N.; Xin, B.S. Decisive Progress in Metallocene-Catalyzed Elastomer Synthesis. Macromolecules 2008, 41, 4095-4101.

29. Thakur, V.; Shan, C.L.P.; Li, G. Sponge EPDM by design. Plast. Rubber Compos. 2019, 48, $32-41$.

30. Ver Strate, G. in Encyclopedia of Polymer Science and Engineering; John Wiley and Sons: New York, 1986, vol. 6, pp. 522-564.

31. Natta, G.; Pasquon, I.; Zambelli, A. Stereospecific catalysts for the head-to-tail polymerization of propylene to a crystalline syndiotactic polymer. J. Am. Chem. Soc. 1962, 84, 1488-1490.

32. Giannetti, E.; Mazzocchi, R.; Albizzati, E.; Fiorani, T.; Milani, F. Homogenoues Ziegler-Natta catalysis: Efficiency improvement of vanadium catalyst systems by tributyltin hydride for ethylene/propylene/diene terpolymerization. Makromol. Chem. 1984, 185, 2133-2151.

33. Cesca, S. The chemistry of unsaturated ethylene-propylene-based terpolymers. Macromol. Rev. 1975, $10,1-230$.

34. Giannetti, E.; Mazzocchi, R.; Albizzati, E.; Fiorani, T. Homogeneous Ziegler-Natta catalysis: Efficiency improvement of vanadium catalyst systems by tributyltin hydride for ethylene/propylene/diene terpolymerization. Makromol. Chem. 1984, 185, 2133-2151. 
35. Zanchin, G.; Bertini, F.; Vendier, L.; Ricci, G.; Lorber, C.; Leone, G. Copolymerization of ethylene with propylene and higher $\alpha$-olefins catalyzed by (imido)vanadium(IV) dichloride complexes. Polym. Chem. 2019, 10, 6200-6216.

36. Zanchin, G.; Vendier, L.; Pierro, I.; Bertini, F.; Ricci, G.; Lorber, C.; Leone, G. Homo- and CoPolymerization of Ethylene with Cyclic Olefins Catalyzed by Phosphine Adducts of (Imido)vanadium(IV) Complexes. Organometallics 2018, 37, 3181-3195.

37. Randall, C. J. A review of high resolution liquid ${ }^{13}$ Carbon nuclear resonance characterizations of ethylene-based polymers. J. Macromol. Sci, Part C. 1989, 29, 201-317.

38. Hasan, T.; Ikeda, T., Shiono, T. Homo- and copolymerization of norbornene derivatives with ethene by ansa-fluorenylamidodimethyltitanium activated with methylaluminoxane. J. Polym. Sci. Pol. Chem. 2007, 45, 4581-4587.

39. Leone, G.; Pierro, I.; Zanchin, G.; Forni, A.; Bertini, F.; Rapallo, A.; Ricci, G. Vanadium(III)catalyzed copolymerization of ethylene with norbornene: Microstructure at tetrad level and reactivity ratios. J. Mol. Cat. A: Chem. 2016, 424, 220-231.

40. Lorber, C.; Vendier, L. Novel aspects of the transamination reaction between $\operatorname{Ti}\left(\mathrm{NMe}_{2}\right)_{4}$ and primary amines. Dalton Trans. 2013, 42, 12203-12219.

41. Mapping composition drift requires laborious and time-consuming polymer fractionation and multi-sample special analysis. See for example, Carson, W.W.; Dwyer, J.L.; Bounajny, B. Copolymer Compositional Drift across Molecular Weight Measured by LC-FTIR. Int. J. Polym. Anal. Ch. 2008, 13, 462-470.

42. Benkoski, J.J.; Fredrickson, G.H.; Kramer, E.J. Effects of Composition Drift on the Effectiveness of Random Copolymer Reinforcement at Polymer-Polymer Interfaces. J. Poly. Sci. Pol. Phys. 2001, 39, 2363-2377.

43. Watanabe, K.; Nakano, S. Development of EPDM with Excellent Cold Resistance. R\&D Report Sumitomo Chemical Asia Pte Ltd; “SUMITOMO KAKUGO”, vol. 2018. 
44. Leone, G.; Mauri, M.; Losio, S.; Bertini, F.; Ricci, G.; Porri, L. Copolymerization of ethylene with a-olefins and cyclic olefins catalyzed by a Ti(IV) diisopropoxy complex bearing a tridentate [O-,S,O-]-type bis(phenolato) ligand. Polym. Chem. 2014, 5, 3412-3423.

45. Leone, G.; Canetti, M.; Pierro, I.; Zanchin, G.; De Rosa, C.; Ricci, G.; Bertini, F. (Micro)structure, thermal behavior and mechanical properties of ethylene-propylene-1-octadecene terpolymers from chain-walking polymerization of 1-octadecene. Polymer 2019, 166, 27-37.

46. O’Connor, K.S.; Watts, A.; Vaidya, T.; LaPointe, A.M.; Hillmyer, M.A.; Coates, G.W. Controlled Chain Walking for the Synthesis of Thermoplastic Polyolefin Elastomers: Synthesis, Structure, and Properties. Macromolecules 2016, 49, 18, 6743-6751.

47. Bassi, W.; Corradini, P.; Fagherazzi, G.; Valvassori, A. Crystallization of high ethylene EPDM terpolymers in the stretched state. Eur. Polym. J. 1970, 6, 709-718.

48. Auriemma, F.; Scoti, M ; Di Girolamo, R.; Malafronte, A.; De Rosa, C.; Van Duin, M. ; Effect of stretching on the crystallization of un-crosslinked ethylene/propylene(/diene) random copolymers. Polymer 2020, 199, 122540.

49. Elkoun, S.; Gaucher-Miri, V.; Séguéla, R. Tensile yield and strain hardening of homogenous ethylene copolymers compared with heterogeneous copolymers. Mater. Sci. Eng. 1997, A234-236, $83-86$.

50. Hong, M.; Pan, L.; Li, B.-X., Li, Y.-S. Synthesis of novel poly(ethylene-ter-1-hexene-terdicyclopentadiene)s using bis( $\beta$-enaminoketonato)titanium catalysts and their applications in preparing polyolefin-graft-poly( $\varepsilon$-polycaprolactone). Polymer 2010, 51, 3636-3643.

51. Berthoud, A.; van Doremale, G.; Quiroga Norambuena, V.; Scott, R.T.W. Catalyst system and a process for the preparation of a polymer using the same. WO2015052184A1, 2015.

52. Kennedy, M.A.; Peacock, A.J.; Failla, M.D.; Lucas, J.C.; Mandelkern, L. Tensile Properties of Crystalline Polymers: Random Copolymers of Ethylene. Macromolecules 1995, 28, 1407-1421.

53. Mullins, L. Softening of Rubber by Deformation. Rubber Chem. Technol. 1969, 42, 339-362.

54. The Physics of Glassy Polymers, 1997, Editors: Haward, R.N. (Ed.), ISBN 978-94-011-5850-3. 
55. Minick, J.; Moet, A.; Hiltner, A.; Baer, E.; Chum, S.P. Crystallization of very low density copolymers of ethylene with $\alpha$-olefins. J. Appl. Polym. Sci. 1995, 58, 1371-1384.

56. Bensason, S.; Minick, J.; Moet, A.; Chum, S.; Hiltner, A.; Baer, E. Classification of homogeneous ethylene-octene copolymers based on comonomer content. J. Polym. Sci. Pol. Phys. 1996, 34, 1301-1315.

57. Hölzer, S.; Menzel, M.; Zia, Q.; Schubert, U.S.; Beiner, M.; Weideisch, R. Blends of ethyleneoctene copolymers with different chain architectures - Morphology, thermal and mechanical behavior. Polymer 2013, 54, 5207-5213. 